\title{
Dissection of the ATPase active site of McdA reveals the sequential steps essential for carboxysome distribution
}

Pusparanee Hakim $^{1}$ and Anthony G. Vecchiarelli ${ }^{1 *}$

Department of Molecular, Cellular, and Developmental Biology, University of Michigan, Ann Arbor, MI, USA.

*Corresponding Author Email Address: ave@umich.edu

Running Title: McdA ATP-cycle distributes carboxysomes

\author{
Abbreviations: \\ BMC - Bacterial Microcompartment \\ $\mathrm{mNG}$ - monomeric NeonGreen \\ mTQ - monomeric Turquoise2 \\ McdA - Maintenance of Carboxysome Distribution protein A \\ McdB - Maintenance of Carboxysome Distribution protein B \\ ParA - Partition protein A \\ ParB - Partition protein B \\ ATP - Adenosine triphosphate \\ AMPPNP - Adenylyl-imidodiphosphate \\ nsDNA - non-specific DNA \\ DAPI - 4',6-diamidino-2-phenylindole
}

\section{Keywords:}

Cyanobacteria, ParA ATPase, McdB, Subcellular Organization 


\section{ABSTRACT}

2 Carboxysomes, the most prevalent and well-studied anabolic bacterial microcompartment, play a central

3 role in efficient carbon fixation by cyanobacteria and proteobacteria. In previous studies, we identified the

4 two-component system called McdAB that spatially distributes carboxysomes across the bacterial

5 nucleoid. McdA, a ParA-like ATPase, forms a dynamic oscillating gradient on the nucleoid in response to

6 carboxysome-localized McdB. As McdB stimulates McdA ATPase activity, McdA is removed from the

7 nucleoid in the vicinity of carboxysomes, propelling these proteinaceous cargos toward regions of highest

8 McdA concentration via a Brownian-ratchet mechanism. However, how the ATPase cycle of McdA

9 governs its in vivo dynamics and carboxysome positioning remains unresolved. Here, by strategically

10 introducing amino acid substitutions in the ATP-binding region of McdA, we sequentially trap McdA at

11 specific steps in its ATP cycle. We map out critical events in the ATPase cycle of McdA that allows the

12 protein to bind ATP, dimerize, change its conformation into a DNA-binding state, interact with McdB-

13 bound carboxysomes, hydrolyze ATP and release from the nucleoid. We also find that McdA is a member

14 of a previously unstudied subset of ParA family ATPases, harboring unique interactions with ATP and

15 the nucleoid for trafficking their cognate intracellular cargos. 


\section{INTRODUCTION}

The ParA family of ATPases play major roles in the subcellular organization of bacterial cells, with members involved in the positioning of a wide array of intracellular cargos including plasmids, chromosomes, the divisome, flagella, chemotaxis clusters, and carbon-fixing organelles called carboxysomes (Lutkenhaus, 2012; Vecchiarelli et al., 2012; Kiekebusch and Thanbichler, 2014). How ATP is used to organize such a diversity of genetic and proteinaceous cargos remains unclear. ParA family members are defined by the presence of a deviant Walker A motif, along with Walker A' and

33 Walker B motifs (Koonin, 1993). Aside from these motifs that make up the ATP-binding pocket, few

34 similarities exist at the sequence level. But structurally, all ParA family members solved to date form very

35 similar nucleotide-sandwich dimers (Schumacher et al., 2012, 2019; Zhang and Schumacher, 2017). ATP binding stabilizes dimerization because of an invariant "signature" lysine residue that defines the deviant

37 Walker A box, which makes cross-contacts with the $\gamma$-phosphate of the opposing monomer making up the sandwich dimer (Dunham et al., 2009).

The ParA family is named after its best-studied member. The ParA ATPase is part of tripartite DNA and Funnell, 2014; Badrinarayanan et al., 2015; Jalal and Le, 2020). Cytoplasmic ParA monomers bind ATP and form the ATP-sandwich dimer (Davey and Funnell, 1997; Zhang and Schumacher, 2017). The ParA dimer then undergoes an ATP-specific conformational change that licenses binding to nonspecific DNA in vitro, which equates to binding the bacterial nucleoid in vivo (Hester and Lutkenhaus, 2007;

47 its partner protein, ParB (Pratto et al., 2008). ParB dimers site-specifically load onto the plasmid, or

48 chromosome, to be partitioned via specific binding to a centromere-like site, typically called parS (Baxter

49 and Funnell, 2014; Jalal and Le, 2020). ParB dimers spread from parS onto flanking DNA to form a

50 massive multimeric nucleoprotein complex (Sanchez et al., 2015; Funnell, 2016). This ParB-parS

51 complex can interact with ParA dimers and stimulate its ATPase activity, which is coupled to ParA 
release from the nucleoid (Hwang et al., 2013; Vecchiarelli et al., 2013; Volante and Alonso, 2015). The resulting ParA depletion zone that forms around the ParB-parS complex also provides a ParA

54 concentration gradient on the nucleoid. In this Brownian-ratchet mechanism, ParB-parS complexes on newly replicated chromosomes or plasmids are bidirectionally segregated to opposing cell-halves as they chase higher concentrations of ParA along the nucleoid in opposing directions (Vecchiarelli et al., 2010, 2014).

A growing list of protein-based cargos have been shown to also require a ParA-type ATPase for their subcellular organization, including carboxysomes (Lutkenhaus, 2012; Vecchiarelli et al., 2012).

Carboxysomes are carbon-fixing organelles found in all cyanobacteria and most carbon-fixing proteobacteria (Turmo et al., 2017), and are responsible for roughly a third of global carbon fixation (Cohen and Gurevitz, 2006). By encapsulating the enzymes Ribulose-1,5-bisphosphate carboxylase/oxygenase (Rubisco) and carbonic anhydrase in a selectively permeable protein shell, the resulting $\mathrm{CO}_{2}$-rich microenvironment within carboxysomes ensures that carboxylation of ribulose-1,5bisphosphate is favored over the undesired process of photorespiration where $\mathrm{O}_{2}$ is fixed instead of $\mathrm{CO}_{2}$ (Kerfeld et al., 2018). Despite the importance of carboxysomes to the global carbon cycle, the mechanisms underlying their subcellular organization remains unclear.

In 2010, Savage and colleagues showed that a ParA-like ATPase, now termed Maintenance of carboxysome distribution protein $\underline{\mathrm{A}}(\mathrm{McdA})$, was required for the equidistant positioning of carboxysomes down the length of the rod-shaped cyanobacterium Synechococcus elongatus PCC7942 (henceforth S. elongatus) (Savage et al., 2010). More recently, we found that McdA functions with a partner protein, called $\mathrm{McdB}$, which associates with the carboxysome cargo and is required for the dynamic oscillatory behavior of McdA in vivo (MacCready et al., 2018). ATP-bound McdA has nonspecific DNA binding activity and McdB stimulates McdA ATPase activity as well as its release from a non-specific DNA substrate in vitro. From these biochemical findings, we proposed that McdB-bound carboxysomes locally stimulate the release of McdA from the nucleoid, and the resulting McdA gradients are then used to drive the movement and equidistant positioning of carboxysomes across the nucleoid 
region of the cell; akin to DNA partitioning by ParABS systems. However, it remains to be determined how the ATP cycle of McdA governs the molecular events required for its dynamic oscillatory patterning and the positioning of McdB-bound carboxysomes across the nucleoid.

There are notable differences that set S. elongatus McdA apart from classical ParA family ATPases.

82 For example, the signature lysine residue that defines the ParA family is absent in the deviant Walker A

83 box of McdA. Also intriguing was the finding that McdA possesses a substantially higher ATPase activity

84 compared to ParA ATPases involved in DNA partitioning (Ah-Seng et al., 2009; Vecchiarelli et al., 2010;

85 MacCready et al., 2018). These differences drove us to dissect the molecular events of carboxysome

86 positioning by McdA and identify how these steps are coupled to its ATP cycle.

Despite these differences, it was recently shown that an McdA homolog shares the adenine-nucleotide sandwich dimer structure solved for several other ParA family ATPases (Schumacher et al., 2019)

(Figure 1A). Additionally, many of the invariant amino acids critical for ATP-dependent functions are 2010, 2013), chromosomes (Leonard et al., 2005), the divisome (Lutkenhaus and Sundaramoorthy, 2003; Kiekebusch et al., 2012; Schumacher et al., 2017), flagella (Ono et al., 2015; Schuhmacher et al., 2015), and chemotaxis clusters (Roberts et al., 2012; Ringgaard et al., 2014) (Summary in Figure 1C, detailed 


\section{RESULTS:}

\section{Strategy for trapping and imaging McdA at specific steps of its ATPase cycle}

We performed in vivo fluorescence microscopy to determine how McdA dynamics and carboxysome organization were altered for McdA mutants trapped at specific steps of its ATP cycle. To visualize carboxysomes, the fluorescent protein monomeric Turquoise2 (mTQ) was fused to the C-terminus of the small subunit of the Rubisco enzyme (RbcS) yielding RbcS-mTQ. RbcS-mTQ was expressed using a second copy of its native promoter (inserted at neutral site 1) in addition to wild-type $r b c S$ at its native

111 locus. To simultaneously image the McdA trap mutants in our carboxysome reporter strain, the amino acid substitutions were made in the ATP-binding pocket of an McdA variant that was N-terminally fused to the fluorescent protein monomeric NeonGreen (mNG) (Shaner et al., 2013). We have previously shown that $\mathrm{mNG}-\mathrm{McdA}$ is fully functional for carboxysome positioning when expressed as the only copy of McdA at its native locus (MacCready et al., 2018). Finally, we also performed Phase Contrast imaging

117 in $m c d A$ or $m c d B$ deletion strains triggers cell elongation, which we proposed is a response to carbon limitation (Rillema et al., 2020).

\section{ATP-binding and dimerization mutants of McdA are diffuse in the cytoplasm and carboxysomes} are mispositioned.

We first set out to determine the in vivo localization pattern of McdA when unbound from ATP, and its impact on carboxysome positioning. We substituted the invariant catalytic Lysine to an Alanine

124 (K15A) or Glutamine (K15Q) in the deviant Walker A box of McdA (Figure 1B). Synonymous

125 mutations in several other ParA-type ATPases have been shown to prevent ATP-binding (Figure 1C). In 126 wild-type S. elongatus cells, as shown previously, mNG-McdA oscillates on the nucleoid to equidistantly

127 position RbcS-mTQ-labeled carboxysomes down the long axis of the cell (Figure 2A). Both ATP-

128 binding mutants of McdA no longer oscillated on the nucleoid, but rather were found to be diffuse in the 129 cytoplasm and carboxysomes were mispositioned (Figure 2, B-C). We then substituted the invariant 
Glycine to a Valine (G11V) in the deviant Walker A box of McdA (see Figure 1, B-C), which allows for ATP-binding, but the bulky side-chain of Valine sterically prevents dimerization (Lutkenhaus, 2012). As with the ATP-binding mutants, the dimerization mutant of McdA was also diffuse in the cytoplasm, and carboxysomes were no longer uniformly distributed in the cell (Figure 2D).

When we compared the nearest-neighbor spacing of carboxysome foci as a function of cell length, wild-type showed the same uniform spacing $(0.6 \pm 0.2 \mu \mathrm{m})$ regardless of cell length (Figure 2 , E-F). All three mutants, on the other hand, displayed increased spacing, and variability in spacing, as cell length increased (Figure 2, E-F). The average cell lengths of the ATP-binding and dimerization mutants were significantly longer compared to wild-type (Figure 2G); a change in cell morphology that mirrors the $\Delta m c d A$ phenotype (Supplementary Figure S1A) (Rillema et al., 2020).

The increased spacing resulted in fewer carboxysome foci per unit cell length (Figure $2 \mathrm{H})$.

141 Comparing the fluorescence intensity of carboxysome foci suggested that the increased spacing in all 142 three mutant populations was the result of carboxysome aggregation (Figure 2I). Overall, McdA mutant strains defective for ATP-binding and dimerization displayed a cell elongation phenotype, and possessed

144 few and irregularly-spaced carboxysome aggregates. These phenotypes match what we have previously observed in the $m c d A$ deletion strain (Rillema et al., 2020), which suggests a complete loss of function in carboxysome positioning when McdA cannot bind ATP and dimerize.

\section{ATP-binding and dimerization are required for McdA to position carboxysomes on the nucleoid}

Plasmids deleted for their ParA-type partitioning system are no longer distributed along the nucleoid.

151 Vecchiarelli et al., 2012; Planchenault et al., 2020). We have shown that nucleoid exclusion also occurs

152 for carboxysomes in S. elongatus strains deleted for $m c d A$ or $m c d B$ (MacCready et al., 2018). We set out 153 to determine if carboxysomes are nucleoid excluded in the ATP-binding and dimerization mutants of

154 McdA. Due to the polyploid nature of S. elongatus, DAPI staining does not easily resolve the nucleoid 155 region from the cytoplasm (Figure S1B). We therefore used the gyrase inhibitor ciprofloxacin to induce 
nucleoid compaction, which increased the cytoplasmic space observable by epifluorescence microscopy.

Conveniently, when wild-type $S$. elongatus cells were treated with ciprofloxacin, mNG-McdA still oscillated on the compacted nucleoid (Movie S1), and carboxysomes were still distributed over the nucleoid region of the cell and not in the cytoplasmic spaces (Figure 2J). The ATP-binding and dimerization mutants of $\mathrm{mNG}-\mathrm{McdA}$, on the other hand, remained diffuse in the cytoplasm and carboxysomes were nucleoid excluded, but in a surprising manner (Figure 2, K-M). Rather than having carboxysomes randomly distributed in the cytoplasmic region of the cell, the carboxysome aggregates butted-up against the ends of the compacted nucleoids (Figure 2, K-M merged panels, and Figure et al., 2020), suggesting this is a widespread mesoscale phenomenon for both genetic and proteinaceous complexes in a bacterial cell.

Many ParA family ATPases are monomeric in their apo forms and dimerize upon ATP-binding,

\section{The ATP-Trap mutant McdA[D39A] does not associate with the nucleoid or McdB in vivo}

To solve the sandwich-dimer structure of an McdA homolog from the cyanobacterium Cyanothece sp. PCC 7424, the Schumacher group made an ATP-trap mutant by substituting the catalytic Aspartate residue to an Alanine in the Walker A' box (see Figure 1, A-B) (Schumacher et al., 2019). Synonymous

178 interaction with their cognate ParB, but are deficient in ATP-hydrolysis (see Figure 1C). We made the

179 corresponding mutation in McdA (D39A) to determine the in vivo localization pattern of an McdA mutant

180 presumably trapped as an ATP-bound dimer, and its effect on carboxysome positioning. Unexpectedly, 181 mNG-McdA[D39A] was diffuse in the cytoplasm and carboxysomes were mispositioned in a manner that 
was identical to our ATP-binding and dimerization mutants of McdA (Figure S2A). The data suggests

McdA[D39A] cannot bind the nucleoid due to a loss in non-specific DNA binding activity. The

Schumacher group showed that ATP-bound McdA[D38A] from Cyanothece can dimerize and bind a nonspecific DNA substrate in vitro (Schumacher et al., 2019), however the interaction affinity with DNA was not compared to wild-type McdA. Since S. elongatus McdA is highly insoluble, we purified the McdA homolog from Cyanothece (CtMcdA) and its ATP-trap variant $C t \mathrm{McdA}[\mathrm{D} 38 \mathrm{~A}]$ (used to solve the McdA structure), and found via Electrophoretic Mobility Shift Assays that $C t \operatorname{McdA}[\mathrm{D} 38 \mathrm{~A}]$ has significantly reduced DNA-binding activity compared to wild-type (Figure S2B), which is consistent with our in vivo observations of the corresponding mutant in S. elongatus (Figure S2A). We also performed Bacterial

Two-Hybrid assays and found that while wild-type McdA showed a strong interaction with McdB, McdA[D39A] did not (Figure S2C), which also explains our in vivo observations of this mutant in $S$. elongatus (Figure S2A). We propose the ATP-trapped dimer of McdA[D39A] does not go through the conformational change that licenses nucleoid binding, which our data suggest is a prerequisite for McdB interaction and distributing carboxysomes over the nucleoid.

\section{The ATP-Trap mutant MedA[K15R] locks onto MedB-bound carboxysomes}

We set out to construct another ATP-trap mutant of McdA that can adopt the nucleoid binding state and interact with McdB. Arguably the best studied ATP-trap mutant from the ParA family of ATPases comes from the P1 plasmid partitioning system (Fung et al., 2001). Mutating the catalytic Lysine to an Arginine in the deviant Walker A box of P1 ParA (K122R) has shown robust in vitro and in vivo phenotypes (see Figure 1, B-C). In vitro, ParA[K122R] can bind ATP, dimerize, and bind non-specific DNA with an affinity comparable to wild-type, but irreversibly associates with ParB because ParB cannot

204 stimulate the ATPase activity required for releasing this association (Fung et al., 2001; Vecchiarelli et al., 205 2013). In vivo, ParA[K122R] results in a worse-than-null and dominant-negative phenotype called Par ${ }^{\mathrm{PD}}$

206 for "propagation-defective", whereby plasmids are less stable than when they have no partition system at 207 all (Youngren and Austin, 1997). Given the severity of the mutation, the mechanism for the $\operatorname{Par}^{\mathrm{PD}}$ 
phenotype has not been directly identified in vivo. However, the inability to disassemble the DNA-

ParA[K122R]-ParB-plasmid complex in vitro suggests a likely mechanism (Hwang and Vecchiarelli et al., 2013).

Strikingly, the corresponding ATP-trap mutant in mNG-McdA (K15R) resulted in nearly complete colocalization with carboxysomes (Figure 3A). When $m c d B$ was deleted from this strain, mNG$\operatorname{McdA}[\mathrm{K} 15 \mathrm{R}]$ no longer associated with carboxysomes; instead coating the nucleoid thus showing its ability to still bind non-specific DNA (Figure 3B). The data suggest that the ATP-trap mutant,

215 McdA[K15R], locks carboxysomes onto the nucleoid via an irreversible interaction between McdA and McdB. Consistently, Bacterial-2-Hybrid analysis showed that McdA[K15R] associates more strongly with McdB compared to wild-type McdA (Figure 3C), while all other McdA mutants studied thus far showed no interaction with McdB (Figure S2C). intensities; a phenotype that was dependent on the presence of McdB (Figure 3D). Consistent with carboxysome aggregation, the McdA[K15R] mutant displayed fewer carboxysome foci per unit cell disaggregate and distribute carboxysomes in the cell.

\section{The ATP-Trap mutant MedA[K15R] locks McdB-bound carboxysomes onto the nucleoid} carboxysome spacing closer to that of wild-type (Figure 3F). Unique to the McdA[K15R] mutant, carboxysome foci were enriched within the midcell region (Figure S3). Also unlike all other McdA mutants described thus far, which were diffuse in the cytoplasm with nucleoid-excluded carboxysomes,

232 mNG-McdA[K15R] strongly colocalized with carboxysomes over ciprofloxacin-compacted nucleoids

233 (Figure 3H). In the $\Delta m c d B$ background, mNG-McdA[K15R] remained associated with the compacted 
nucleoid, once again showing this mutant retains non-specific DNA binding activity, while carboxysomes became nucleoid excluded (Figure 3I). Together, the data show that the ATP-trap mutant McdA[K15R] locks carboxysome aggregates onto the nucleoid via an irreversible interaction with McdB.

Finally, we asked if locking carboxysome aggregates onto the nucleoid in the McdA[K15R] strain resulted in the same cell elongation phenotype found for all other McdA mutants described thus far.

239 Surprisingly, the McdA[K15R] strain did not elongate (Figure 3J). In fact, the McdA[K15R] cells were slightly smaller than wild-type. When $m c d B$ was deleted in the McdA[K15R] strain, the cell elongation phenotype returned. The findings suggest that the pseudo-positioning of carboxysome aggregates locked onto the nucleoid is sufficient to prevent cell elongation induced by the mispositioning of nucleoidexcluded carboxysome aggregates in null mutants of the McdAB system (Rillema et al., 2020).

\section{McdA represents an unstudied subclass of ParA-family ATPases}

247 (Schumacher et al., 2019), McdA lacks the classical "Signature Lysine" residue in the deviant Walker A

251 signature Lysine, Lys151 interacts with the ATP molecule bound in the adjacent McdA monomer;

252 making the same cross contacts to the oxygen atom connecting the $\beta$ - and $\gamma$-phosphates. Sequence

253 alignments of McdA homologs that lack the classical signature Lysine in the deviant Walker A box,

254 invariably encode for a lysine that corresponds to Lys151 in S. elongatus McdA (Figure 4A). Given the

255 McdA structure, sequence conservation, and biochemical data suggesting Lys151 is important for ATP

256 binding and dimerization, we next observed the effect of mutating Lys 151 to an Alanine in vivo. The

257 majority of mNG-McdA[K151A] remained diffuse in the cytoplasm, while a minor fraction colocalized

258 with few and irregularly spaced carboxysome aggregates (Figure 4B). Carboxysome foci intensity,

259 spacing and average cell length were identical to that found for the other ATP-binding and dimerization 
mutants of McdA tested in this study (Figure S4, A-D). Also, ciprofloxacin treatment showed carboxysome aggregates were nucleoid excluded, and once again butted-up against the nucleoid poles

262 (Figure 4C). The findings highlight the importance of Lys151 as the "Signature Lysine" for an unstudied

263 ParA subclass, in forming the ATP-bound McdA dimer competent for nucleoid binding and positioning

264 carboxysomes.

Moving the Signature Lysine of McdA into the Walker A box reconstitutes carboxysome pseudo-

Remarkably, Lys 151 of the McdA structure overlays exceptionally well onto the signature lysine position in the deviant Walker-A box of classical ParA family members (Schumacher et al., 2019). This finding suggested that it may be possible to maintain carboxysome positioning with an McdA mutant that

271 has its signature Lysine at position 151 reintroduced into the classical position in the deviant Walker A

272 box at position 10 (see Figure 4A). To make the signature Lysine mutant, McdA[S10K, K151S], we

273 swapped the Serine at position 10 in the deviant Walker A box with the Lysine at position 151. The mNG-McdA[K151S] phenotype mirrored that of McdA[K151A] - largely diffuse in the cytoplasm with nucleoid-excluded carboxysome aggregates (Figure S4E). mNG-McdA[S10K, K151S], on the other hand, largely colocalized with carboxysome foci (Figure 5A). Also, carboxysome spacing (Figure 5B) and intensity (Figure 5C) both trended back towards wild-type values, and ciprofloxacin treatment showed that carboxysomes were now positioned within the nucleoid region of the cell (Figure 5D). Together, the data suggest a pseudo-restoration of carboxysome positioning on the nucleoid. Consistently, the McdA[S10K, K151S] cell population had cell lengths revert back to wild-type (Figure 5E),

281 suggesting this pseudo-positioning of carboxysomes is sufficient to alleviate the cell elongation mutant 282 phenotype (Rillema et al., 2020). 


\section{DISCUSSION}

Members of the ParA family of ATPases position a wide variety of genetic and proteinaceous cargos involved in diverse biological processes (Lutkenhaus, 2012; Vecchiarelli et al., 2012; Kiekebusch and Thanbichler, 2014). ATP cycling by the ParA ATPase is critical for its dynamic patterning behavior in the cell as well as its positioning activity on the cognate cargo. We recently found that the McdAB system is widespread across cyanobacteria and carboxysome-containing proteobacteria (MacCready et al. 2020; MacCready and Tran et al. 2021), yet it remains unknown how the ATPase cycle of McdA controls its oscillatory dynamics and its function in distributing carboxysomes across the nucleoid length. Several well-researched amino acid substitutions in the conserved ATP-binding site of ParA family ATPases have been used to trap the ATP cycle at specific steps. These trap mutants have served as useful probes for dissecting the molecular steps involved in ParA-based positioning reactions (Summary in Figure 1C, detailed in Table S1). To dissect how ATP mediates McdA function in positioning fluorescently-labelled carboxysomes, we introduced synonymous amino acid substitutions in the ATP-binding pocket of fluorescently-labelled McdA to trap it at specific steps of the ATP cycle. The phenotypes of these trap mutants have allowed us to correlate the known biochemistry of well-studied ParA family ATPases with specific steps in McdA action we observed here in vivo.

Overall we find that ATP-binding, dimerization, and an ATP-specific conformational change in McdA are all prerequisite steps for McdA to associate with the nucleoid via non-specific DNA binding activity (Figure 6A). Our findings suggest that McdB-bound carboxysomes can only interact with McdA in this DNA-binding state. Nucleoid-associated McdA tethers McdB-bound carboxysomes to the nucleoid. But ultimately, McdB stimulates ATP-hydrolysis by McdA, which reverts McdA back into its monomeric form that can no longer bind the nucleoid in the vicinity of the carboxysome. Through this Brownian-ratchet mechanism (MacCready et al., 2018), McdB-bound carboxysomes are uniformly distributed as they locally generate McdA depletion zones on the nucleoid, and then move up the resulting McdA gradient towards higher concentrations (Figure 6B). 
McdA mutants unable to bind ATP, dimerize, or undergo the ATP-specific conformational change required for nucleoid binding were diffuse in the cytoplasm and carboxysomes were observed as nucleoid-excluded aggregates. These mutant strains also displayed cell elongation. We have recently shown that $m c d A$ and $m c d B$ deletion strains also elongate (Rillema et al., 2020). Heterotrophic bacteria

317 have been shown to undergo cell elongation as a carbon-limitation response (Rangarajan et al., 2020). We

318 also recently proposed that carboxysome aggregation results in decreased carbon-fixation efficiency, and

319 that cell elongation is a response triggered by the resulting carbon limitation in this photoautotroph

320 (Rillema et al., 2020). Since the phenotype of these McdA trap mutants mirror the $m c d A$ deletion strain, 321 our findings suggest a complete loss of function in carboxysome positioning when McdA cannot bind 322 ATP, dimerize, and adopt its nucleoid-binding conformation.

\section{Nucleoid-excluded carboxysomes are trapped at the cytoplasm-nucleoid interface}

We previously showed that in $\Delta m c d A$ or $\Delta m c d B$ strains of $S$. elongatus, carboxysomes still fully assemble, but coalesce into nucleoid-excluded aggregates (MacCready et al., 2018). Given the polyploid nature of $S$. elongatus, there is insufficient cytoplasmic space to resolve whether carboxysomes aggregated due to physical interactions with each other, or if they simply coalesced because of nucleoid exclusion. We used the gyrase-inhibitor ciprofloxacin to compact the nucleoid and increase the cytoplasmic space of $S$. elongatus cells. Surprisingly, we found that in the absence of a functional McdAB system, carboxysome aggregates did not diffuse into the increased cytoplasmic space of ciprofloxacintreated cells. Instead, the aggregates were maintained at the cytoplasm-nucleoid interface. It was recently shown that large plasmids lacking their ParA-based partition system, or large DNA circles excised from the chromosome, also localize to this interface (Planchenault et al., 2020). This phenomenon was plasmid-size dependent; only plasmids larger than $100 \mathrm{~kb}$ preferentially localized to the nucleoid edge and did not diffuse into the nucleoid-free cytoplasmic space of the cell. Our findings here show that this preferential localization to the nucleoid edge is not specific to plasmids, but is rather a widespread

337 phenomenon in bacteria for both genetic and proteinaceous complexes on the mesoscale. Given the size- 
dependence of nucleoid-evicted complexes being unable to penetrate the cytoplasm, we believe the most

parsimonious explanation is that carboxysomes, and other mesoscale complexes, perceive the cytoplasmic environment as glassy (Parry et al., 2014); thus exhibit caging and subdiffusive behaviors at the nucleoidcytoplasm interface. carboxysome movement and positioning within the nucleoid region of the cell.

\section{The ATP-trap mutant McdA[K15R] locks carboxysomes onto the nucleoid}

We identified the ATP-trap mutant, McdA[K15R], that locks the nucleoid-McdA-McdBaggregates over the nucleoid. Together the findings show that McdA on the nucleoid transiently interacts with McdB on carboxysomes. McdB then stimulates McdA ATP-hydrolysis and release from the nucleoid in the vicinity of carboxysomes, which allows for continued movement up the resulting McdA gradient. Without the ability to hydrolyze ATP, McdA[K15R] irreversibly associates with McdB and statically tethers carboxysomes to the nucleoid. Since the ATP cycle cannot rest, McdB-bound

357 carboxysomes act as a sink for all McdA[K15R] in the cell, which explains the absence of mNG-

$358 \operatorname{McdA}[\mathrm{K} 15 \mathrm{R}]$ redistribution across the nucleoid.

All McdA mutants that result in nucleoid-excluded carboxysome aggregation also showed a cell 
We have two hypotheses that could explain this phenotype. First, tethering carboxysomes to the nucleoid could allow for pseudo-positioning of carboxysomes. This "pilot-fish" mode of carboxysome positioning and inheritance could sufficiently improve carbon-fixation efficiency, thereby preventing carbon limitation and the cell elongation response. Alternatively, it can be envisioned that irreversibly tethering massive carboxysomes onto the nucleoid can have detrimental effects to a variety of DNA transactions such as DNA replication, transcription, nucleoid organization and compaction, and faithful chromosome segregation. Therefore the shorter cell length could simply be attributed to a slower growth rate.

\section{Swapping the Signature Lysine position in McdA resulted in carboxysome pseudo-positioning on}

McdA represents a previously unstudied subclass of the ParA family, where the signature Lysine residue that defines this ATPase family is located in the C-terminal half of the protein, rather than in the

373 Walker A box (see Figure 4A). We find here that Lysine151 is indeed necessary for McdA to bind the 374 nucleoid and position carboxysomes. Strikingly, we also found that repositioning this Lysine into the 375 classical signature Lysine position in the Walker A box reconstituted carboxysome pseudo-positioning 376 carboxysome spacing and focal intensity trended back to wild-type values. This mutant also reverted back

377 to wildtype cell lengths. However, the oscillatory dynamics observed with wildtype McdA were not 378 reconstituted. Instead, mNG-McdA[S10K, K151S] colocalized with carboxysomes over the nucleoid.

379 This mode of carboxysome positioning is similar to that observed for the P1 plasmid partition system. P1

380 ParB forms punctate foci by loading onto and around a DNA binding site called parS on the plasmid to be 381 partitioned (Erdmann et al., 1999; Sengupta et al., 2010). The ParA ATPase uniformly distributes over 382 the nucleoid, but also forms foci that colocalize with relatively immobile ParB-bound plasmids (Hatano and Niki, 2010). During plasmid partitioning and movement, the colocalized ParA foci disappear and

384 only reappear once the sister plasmids have reached the $1 / 4$ and $3 / 4$ positions of the cell where they once again become relatively immobile. McdA has an ATPase activity two-orders of magnitude greater than 
the Lysine-swap mutant of McdA decreases its voracious ATPase activity, causing it to remain associated with McdB-bound carboxysomes for a longer period of time and adopting a "stick-and-move" mode of carboxysomes positioning over the nucleoid; similar to the P1 plasmid partition reaction described above. believe the answer lies in the difference in cargo copy-number in the cell. ParA-based DNA segregation systems are typically found on bacterial chromosomes and large low-copy plasmids. In both cases, the DNA is replicated and the sister copies are then segregated to opposing halves of the cell prior to division.

394 Carboxysome copy number, on the other hand, can be significantly higher and varies depending on 


\section{MATERIALS AND METHODS:}

\section{Construct design}

All constructs were made using Gibson assembly (Gibson et al., 2009) from PCR fragments or synthesized dsDNA (Integrated DNA Technologies) and verified by Sanger sequencing. For $m c d B$ deletion and native fluorescent fusion gene insertions into the $S$. elongatus genome, constructs were made as previously described (MacCready et al., 2018).

\section{Growth conditions and transformations}

All S. elongatus (ATCC $® 33912^{\mathrm{TM}}$ ) strains were grown in $125 \mathrm{~mL}$ baffled flasks (Corning) in $50 \mathrm{~mL}$ BG11 medium (Sigma) pH 8.3 buffered with 1g/L HEPES. Cells were cultured in a Minitron incubation system (Infors-HT) with the following growth conditions: $60 \mu \mathrm{mol} \mathrm{m}^{-2} \mathrm{~s}^{-1}$ continuous LED 5600K light, $32^{\circ} \mathrm{C}, 2 \% \mathrm{CO}_{2}$, and shaking at 130 RPM. Plasmids were cloned in chemically competent One Shot ${ }^{\mathrm{TM}}$ TOP10 E. coli cells (Thermo Fisher Scientific) in standard manipulation and culture conditions (Green and Sambrook 2012). Transformations of $S$. elongatus cells were performed as previously described (Clerico et al., 2007). Transformant cells were plated on BG-11 agar with $12.5 \mu \mathrm{g} / \mathrm{ml}$ kanamycin, 12.5 $\mu \mathrm{g} / \mathrm{ml}$ chloramphenicol or $25 \mu \mathrm{g} / \mathrm{ml}$ spectinomycin. Single colonies were picked and transferred into 96well plates containing BG-11 medium with corresponding antibiotic concentrations. Complete gene insertions and absence of the wildtype gene were verified via PCR and cultures were removed from antibiotic selection by three series of back dilution prior to imaging.

\section{Ciprofloxacin treatment and nucleoid visualization}

To induce nucleoid compaction, S. elongatus cells were incubated with $50 \mu \mathrm{M}$ ciprofloxacin overnight under normal growth conditions. To visualize the compacted nucleoid region, ciprofloxacin-treated $S$. elongatus cells were harvested by centrifugation at 4,000 $\mathrm{x} g$ for 1 minute. The pelleted cells were then washed and resuspended in $100 \mu \mathrm{l}$ of PBS ( $\mathrm{pH} 7.2)$. DAPI ( $8 \mu \mathrm{l}$ from a $20 \mu \mathrm{g} / \mathrm{ml}$ stock concentration) was added to the cell suspension followed by 20 -minute incubation in the dark at $30^{\circ} \mathrm{C}$. DAPI-stained cells were washed twice with $1 \mathrm{ml} \mathrm{H} 2 \mathrm{O}$, and then resuspended in $100 \mu \mathrm{H}_{2} \mathrm{O}$ prior to visualization using the DAPI channel.

\section{Fluorescence Microscopy}

Exponentially growing cells $\left(2 \mathrm{mls}\right.$ of cells at $\left.\mathrm{OD}_{750} \sim 0.7\right)$ were harvested and spun down at $4,000 \mathrm{x}$ for 1 min, resuspended in $200 \mu 1$ fresh BG-11 and $2 \mu 1$ was then transferred to a $1.5 \%$ UltraPure agarose (Invitrogen) + BG-11 square pad on a glass-bottom dish (MatTek Life Sciences). All fluorescence and phase contrast imaging were performed using a Nikon Ti2-E motorized inverted microscope controlled by NIS Elements software with a SOLA 365 LED light source, a 100X Objective lens (Oil CFI Plan Apochromat DM Lambda Series for Phase Contrast), and a Photometrics Prime 95B Back-illuminated sCMOS camera. mNG-McdA variants were imaged using a "YFP" filter set (C-FL YFP, Hard Coat, High Signal-to-Noise, Zero Shift, Excitation: 500/20nm [490-510nm], Emission: 535/30nm [520-550nm], DichroicMirror: $515 \mathrm{~nm}$ ). RbcS-mTQ labelled carboxysomes were imaged using a "CFP" filter set (C-FL CFP, Hard Coat, High Signal-to-Noise, Zero Shift, Excitation: 436/20nm [426-446nm], Emission: 480/40nm [460-500nm], Dichroic Mirror: 455nm). DAPI fluorescence was imaged using a standard "DAPI" filter set (C-FL DAPI, Hard Coat, High Signal-to-Noise, Zero Shift, Excitation: 350/50nm [325375nm], Emission: 460/50nm [435-485nm], Dichroic Mirror: 400nm). Image analysis was performed using Fiji v1.53b (Schindelin et al., 2012). 


\section{Image Analysis}

Image analysis including cell segmentation, quantification of cell length, foci number, intensity and spacing were performed using Fiji plugin MicrobeJ 5.13I (Ducret et al., 2016). Cell perimeter detection and segmentation were done using the rod-shaped descriptor with default threshold settings. Carboxysome detection was performed using the smoothed foci function with tolerance of 50 and Z-score of 30. Data were exported, further tabulated, graphed and analyzed using GraphPad Prism 9.0.1 for macOS, GraphPad Software, San Diego, California USA, www.graphpad.com.

$478 \mathrm{~N}$-terminal T18 and T25 fusions of McdA, all McdA mutant variants, and McdB were constructed using the plasmids pKT25 and pUT18C. Plasmids were sequence-verified and co-transformed into E. coli BTH101 in both pairwise combinations (Karimova et al., 1998). Several colonies of T18/T25 cotransformants were cultured in LB medium with $100 \mathrm{mg} / \mathrm{ml}$ ampicillin, $50 \mathrm{mg} / \mathrm{ml}$ kanamycin and 0.5 $\mathrm{mM}$ IPTG overnight at $30^{\circ} \mathrm{C}$ with $225 \mathrm{rpm}$ shaking. Overnight cultures were spotted on indicator LB Xgal plates supplemented with $100 \mathrm{mg} / \mathrm{ml}$ ampicillin, $50 \mathrm{mg} / \mathrm{ml}$ kanamycin and $0.5 \mathrm{mM}$ IPTG. Plates were incubated in the dark at $30^{\circ} \mathrm{C}$ up to 48 hours before imaging.

\section{Expression and purification of $C t$ MedA and $C t \operatorname{McdA}$ [D38A]}

Both $C t \mathrm{McdA}$ and $C t \mathrm{McdA}[\mathrm{D} 38 \mathrm{~A}]$ were expressed and purified in a similar manner. For protein production, the expression plasmids for these constructs (Schumacher et al., 2019) were transformed into E. coli $\mathrm{C} 41$ (DE3) cells (Lucigen). Transformants were grown at $37^{\circ} \mathrm{C}$ and $225 \mathrm{rpm}$ until an $\mathrm{OD}_{600}$ of $0.4-$ 0.6 was reached. The culture flasks were rapidly cooled down to $15^{\circ} \mathrm{C}$ on and protein expression was then induced with the addition of $1 \mathrm{mM}$ IPTG. After overnight induction, the cells were pelleted, flash frozen in liquid nitrogen and stored at $-80^{\circ} \mathrm{C}$. Harvested cells were resuspended in Buffer A ( $25 \mathrm{mM}$ Tris- $\mathrm{HCl}$ pH 7.5, $300 \mathrm{mM} \mathrm{NaCl}, 10 \%$ glycerol, $0.5 \mathrm{mM} \mathrm{BME,} 50 \mathrm{mg} / \mathrm{ml}$ lysozyme, $1.25 \mathrm{kU}$ benzonase, 2 Protease Inhibitor Cocktail tablets) and lysed using a probe sonicator with $15 \mathrm{~s}$ on, $15 \mathrm{~s}$ off pulsation for 8 min. The lysate was cleared by centrifugation at $12,000 \mathrm{x}$ g at $4{ }^{\circ} \mathrm{C}$ for $40 \mathrm{~min}$ in a Fiberlite TM F15-8 x 50 cy Fixed Angle Rotor (ThermoFisher Scientific). The resulting lysate was filtered through a $0.45 \mu \mathrm{m}$ syringe filter and loaded onto a $5 \mathrm{ml}$ HiTrap ${ }^{\mathrm{TM}}$ TALON Crude cassette (GE) and eluted with a 0 to $400 \mathrm{mM}$ imidazole gradient. Peak fractions were pooled and concentrated using an Amicon Ultra Centrifugal Device (10 KD MWCO). The concentrated protein sample was passed through a HiPrep 26/10 Desalting Column (GE) equilibrated in Q-Buffer (25mM Tris- $\mathrm{HCl} \mathrm{pH}$ 7.5, $150 \mathrm{mM} \mathrm{NaCl}, 10 \%$ glycerol, $1 \mathrm{mM}$ EDTA, 1mM DTT). The sample was then immediately loaded onto a HiTrap ${ }^{\mathrm{TM}} \mathrm{Q}$ HP $5 \mathrm{ml}$ cassette (GE) equilibrated in Q-Buffer. The protein was eluted with a $150 \mathrm{mM}$ to $2 \mathrm{M} \mathrm{NaCl}$ gradient. Peak fractions were concentrated to no more than $70 \mathrm{mM}$ and flash frozen aliquots were kept at $-80^{\circ} \mathrm{C}$.

\section{DNA binding assay}

Electrophoretic mobility shift assays (EMSAs) were performed in a final reaction volume of $10 \mu \mathrm{l}$ in a buffer containing $50 \mathrm{mM}$ HEPES (pH 7.6), $5 \mathrm{mM} \mathrm{MgCl}_{2}$, and $100 \mathrm{mM} \mathrm{KCl}$ with $10 \mathrm{nM}$ pUC19 plasmid $(2.8 \mathrm{~kb})$ as the supercoiled DNA substrate. At the concentrations indicated, His- $C t$ McdA and His$C t \mathrm{McdA}[\mathrm{D} 38 \mathrm{~A}]$ were incubated for $30 \mathrm{~min}$ at $23^{\circ} \mathrm{C}$ with or without ATP $(1 \mathrm{mM})$. Reactions were then mixed with $1 \mu 180 \%$ glycerol, run on $1 \%$ agarose gel in $1 \mathrm{X}$ TAE at $110 \mathrm{~V}$ for 45 min and stained with ethidium bromide for imaging.

\section{Protein structure visualization and prediction}

Molecular graphics and analyses of protein structures were performed with USCF Chimera, developed by the Resource for Biocomputing, Visualization and Informatics at the University of California, San 
Francisco, with support from NIH P41-GM103311 (Pettersen et al., 2004). Prediction of SeMcdA structure was performed with Phyre2 (Kelley et al., 2015).

\section{ACKNOWLEDGEMENTS}

We would like to thank Joshua MacCready, Kiyoshi Mizuuchi, Maria Schumacher and David Savage for helpful discussions. The pET15b expression vectors used for $C t \mathrm{McdA}$ and $C t \mathrm{McdA}[\mathrm{D} 38 \mathrm{~A}]$ were kind gifts from Maria Schumacher. This work is supported by the National Science Foundation to A.G.V. (Award No. 1817478 and CAREER Award No. 1941966), Rackham Graduate Research Grant to P.H., Rackham Professional Development Grant to P.H., American Society for Microbiology Research Capstone Fellowship to P.H., Margaret Dow Towsley Scholarship to P.H. and by research initiation fund to A.G.V. provided by the MCDB department, University of Michigan.

\section{REFERENCES:}

Ah-Seng, Y, Lopez, F, Pasta, F, Lane, D, Bouet, J-Y (2009). Dual role of DNA in regulating ATP hydrolysis by the SopA partition protein. J Biol Chem 284, 30067-30075.

Ah-Seng, Y, Rech, J, Lane, D, Bouet, J-Y (2013). Defining the role of ATP hydrolysis in mitotic segregation of bacterial plasmids. PLoS Genet 9, e1003956.

Badrinarayanan, A, Le, TBK, Laub, MT (2015). Bacterial chromosome organization and segregation. Annu Rev Cell Dev Biol 31, 171-199.

Barillà, D, Rosenberg, MF, Nobbmann, U, Hayes, F (2005). Bacterial DNA segregation dynamics mediated by the polymerizing protein ParF. EMBO J 24, 1453-1464.

Baxter, JC, Funnell, BE (2014). Plasmid Partition Mechanisms. Microbiol Spectr. 2:PLAS-0023-2014.

Clerico, EM, Ditty, JL, Golden, SS (2007). Specialized techniques for site-directed mutagenesis in cyanobacteria. In: Circadian Rhythms: Methods and Protocols. ed. E. Rosato, New Jersey: Humana Press, $155-171$.

Cohen, Y, Gurevitz, M (2006). The Cyanobacteria - Ecology, Physiology and Molecular Genetics. In: The Prokaryotes: Volume 4: Bacteria: Firmicutes, Cyanobacteria. ed. M. Dworkin, S. Falkow, E. Rosenberg, K-H. Schleifer, E. Stackebrandted. New York: Springer US, 1074-1098.

Corrales-Guerrero, L, He, B, Refes, Y, Panis, G, Bange, G, Viollier, PH, Steinchen, W, Thanbichler, M (2020). Molecular architecture of the DNA-binding sites of the P-loop ATPases MipZ and ParA from Caulobacter crescentus, Nucleic Acids Res 48, Issue 9, 4769-4779.

Davey, M, Funnell, BE (1997). Modulation of the P1 plasmid partition protein ParA by ATP, ADP, and P1 ParB. J Biol Chem 272, 15286-15292.

Ducret, A, Quardokus, EM, Brun, Y V. (2016). MicrobeJ, a tool for high throughput bacterial cell detection and quantitative analysis. Nat Microbiol 1, 1-7.

Dunham, TD, Xu, W, Funnell, BE, Schumacher, MA (2009). Structural basis for ADP-mediated transcriptional regulation by $\mathrm{P} 1$ and P7 ParA. EMBO J 28, 1792-1802. 
Erdmann, N, Petroff, T, Funnell, BE (1999). Intracellular localization of P1 ParB protein depends on ParA and parS. Proc Natl Acad Sci USA 96, 14905-14910.

Fung, E, Bouet, J-Y, Funnell, BE (2001). Probing the ATP-binding site of P1 ParA: partition and repression have different requirements for ATP binding and hydrolysis. EMBO J 20, 4901-4911.

Funnell, BE (2016). ParB Partition Proteins: Complex formation and spreading at bacterial and plasmid centromeres. Front Mol Biosci 3, 44.

Gibson, DG, Young, L, Chuang, RY, Venter, JC, Hutchison, CA, Smith, HO (2009). Enzymatic assembly of DNA molecules up to several hundred kilobases. Nat Methods 6, 343-345.

Green, MR, Sambrook, J (2012). Molecular Cloning: A Laboratory Manual, Fourth Edition. New York: Cold Spring Harbor Laboratory Press.

Hatano, T, Niki, H (2010). Partitioning of P1 ParA plasmids by gradual distribution of the ATPase ParA. Mol Microbiol 78, 1182-1198.

Hatano, T, Yamaichi, Y, Niki, H (2007). Oscillating focus of SopA associated with filamentous structure guides partitioning of F plasmid. Mol Microbiol 64, 1198-1213.

Hester, CM, Lutkenhaus, J (2007). Soj (ParA) DNA binding is mediated by conserved arginines and is essential for plasmid segregation. Proc Natl Acad Sci USA 104, 20326-20331.

Hwang, LC, Vecchiarelli, AG, Han, YW, Mizuuchi, M, Harada, Y, Funnell, BE, Mizuuchi, K (2013).

ParA-mediated plasmid partition driven by protein pattern self-organization. EMBO J 32, 1238-1249.

Jalal, ASB, Le, TBK (2020). Bacterial chromosome segregation by the ParABS system. Open Biol 10, 200097.

Karimova, G, Pidoux, J, Ullmann, A, Ladant, D (1998). A bacterial two-hybrid system based on a reconstituted signal transduction pathway. Proc. Natl. Acad. Sci. USA 95, 5752-5756.

Kelley, LA, Mezulis, S, Yates, CM, Wass, MN, Sternberg, MJ (2016). The Phyre2 web portal for protein modeling, prediction and analysis. Nat Protoc 10, 845-858.

Kerfeld, CA, Aussignargues, C, Zarzycki, J, Cai, F, Sutter, M (2018). Bacterial microcompartments. Nat Rev Microbiol 16, 277-290.

Kiekebusch, D, Michie, KA, Essen, LO, Löwe, J, Thanbichler, M (2012). Localized dimerization and nucleoid binding drive gradient formation by the bacterial cell division inhibitor MipZ. Mol Cell 46, 245259.

Kiekebusch, D, Thanbichler, M (2014). Spatiotemporal organization of microbial cells by protein concentration gradients. Trends Microbiol 22, 65-73.

Koonin, EV (1993). A superfamily of ATPases with diverse functions containing either classical or deviant ATP-binding motif. J Mol Biol 229, 1165-1174.

Leonard, TA, Butler, PJ, Lowe, J (2005). Bacterial chromosome segregation: structure and DNA binding of the Soj dimer - a conserved biological switch. EMBO J 24, 270-282.

Libante, V, Thion, L, Lane, D (2001). Role of the ATP-binding site of SopA protein in partition of the F plasmid. J Mol Biol 314, 387-399. 
Lin, L, Osorio Valeriano, M, Harms, A, Søgaard-Andersen, L, Thanbichler, M (2017). Bactofilinmediated organization of the ParABS chromosome segregation system in Myxococcus xanthus. Nat Commun 8, 1817.

Lutkenhaus, J (2012). The ParA/MinD family puts things in their place. Trends Microbiol 20, 411-418. Lutkenhaus, J, Sundaramoorthy, M (2003). MinD and role of the deviant Walker A motif, dimerization and membrane binding in oscillation. Mol Microbiol 48, 295-303.

MacCready, JS, Basalla, JL,Vecchiarelli, AG (2020). Origin and evolution of carboxysome positioning systems in cyanobacteria. Mol Biol Evol 37, 1434-1451.

MacCready, JS, Hakim, P, Young, EJ, Hu, L, Liu, J, Osteryoung, KW, Vecchiarelli, AG, Ducat, DC (2018). Protein gradients on the nucleoid position the carbon-fixing organelles of cyanobacteria. eLife, 7:e39723.

MacCready, JS, Tran, L, Basalla, JL, Hakim, P, Vecchiarelli, AG (2021). The McdAB system positions $\alpha$-carboxysomes in proteobacteria. Mol Microbiol 00, 1-21.

Ono, H, Takashima, A, Hirata, H, Homma, M, Kojima, S (2015). The MinD homolog FlhG regulates the synthesis of the single polar flagellum of Vibrio alginolyticus. Mol Microbiol 98, 130-141.

Park, KT, Wu, W, Lovell, S, Lutkenhaus, J (2012). Mechanism of the asymmetric activation of the MinD ATPase by MinE. Mol Microbiol 85,271-281.

Parry, BR, Surovtsev, IV, Cabeen, MT, O’Hern, CS, Dufresne, ER, Jacobs-Wagner, C (2014). The bacterial cytoplasm has glass-like properties and is fluidized by metabolic activity. Cell 156, 183-194.

Pettersen, EF, Goddard, TD, Huang, CC, Couch, GS, Greenblatt, DM, Meng, EC, Ferrin, TE (2004). UCSF Chimera-A visualization system for exploratory research and analysis. J Comput Chem 25,1605 1612.

Planchenault, C, Pons, CM, Shiavon, C, Siguier, P., Rech, J, Guynet, C, Dauverd-Girault, J, Cury, J, Rocha, EPC, Junier, I, et al. (2020). Intracellular positioning systems limit the entropic eviction of secondary replicons toward the nucleoid edges in bacterial cells. J Mol Biol 432, 745-761.

Pratto, F, Cicek, A, Weihofen, WA, Lurz, R, Saenger, W, Alonso, JC (2008). Streptococcus pyogenes pSM19035 requires dynamic assembly of ATP-bound ParA and ParB on parS DNA during plasmid segregation. Nucl Acids Res 36, 3676-3689.

Ptacin, JL, Gahlmann, A, Bowman, GR, Perez, AM, von Diezmann, ARS, Eckart, MR, Moerner, WE, Shapiro, L (2014). Bacterial scaffold directs centromere movement. Proc Natl Acad Sci USA 111, E2046E2055.

Ptacin, JL, Lee, SF, Garner, EC, Toro, E, Eckart, M, Comolli, LR, Moerner, WE, Shapiro, L (2010). A spindle-like apparatus guides bacterial chromosome segregation. Nat Cell Biol 12, 791-798.

Rangarajan, AA, Koropatkin, NM, Biteen, JS (2020). Nutrient-dependent morphological variability of Bacteroides thetaiotaomicron. Microbiology 166, 624-628.

Rillema, R, MacCready, JS, Vecchiarelli, AG (2020). Cyanobacterial growth and morphology are influenced by carboxysome positioning and temperature. BioRxiv, 2020.06.01.127845.

Ringgaard, S, Zepeda-Rivera, M, Wu, X, Schirner, K, Davis, BM, Waldor, MK (2014). ParP prevents dissociation of CheA from chemotactic signaling arrays and tethers them to a polar anchor. Proc Natl Acad Sci USA 111, E255-E264. 
639 Ringgaard, S, Van Zon, J, Howard, M, Gerdes, K (2009). Movement and equipositioning of plasmids by 640 ParA filament disassembly. Proc Natl Acad Sci USA 106, 19369-19374.

641 Roberts, MAJ, Wadhams, GH, Hadfield, KA, Tickner, S, Armitage, JP (2012). ParA-like protein uses 642 nonspecific chromosomal DNA binding to partition protein complexes. Proc Natl Acad Sci USA 109, $6436698-6703$.

644 Sanchez, A, Cattoni, DI, Walter, J-C, Rech, J, Parmeggiani, A, Nollmann, M, Bouet, J-Y (2015).

645 Stochastic self-assembly of ParB proteins builds the bacterial DNA segregation apparatus. Cell Syst 1, $646 \quad 163-173$.

647 Savage, DF, Afonso, B, Chen, AH, Silver, PA (2010). Spatially ordered dynamics of the bacterial carbon 648 fixation machinery. Science 327, 1258.

649 Schindelin, J, Arganda-Carreras, I, Frise, E, Kaynig, V, Longair, M, Pietzsch, T, Preibisch, S, Rueden, 650 C, Saalfeld, S, Schmid, B, et al. (2012). Fiji: An open-source platform for biological-image analysis. Nat 651 Methods 9, 676-682.

652 Schuhmacher, JS, Rossman, F, Dempwolff, F, Knauer, C, Altegoer, F, Steinchen, W, Dörrich, AK, 653 Klingl, A, et al. (2015). MinD-like ATPase FlhG effects location and number of bacterial flagella during 654 C-ring assembly. Proc Natl Acad Sci USA 112, 3092-3097.

655 Schumacher, D, Bergeler, S, Harms, A, Vonck, J, Huneke-Vogt, S, Frey, E, Søgaard-Andersen, L (2017).

656 The PomXYZ proteins self-organize on the bacterial nucleoid to stimulate cell division. Dev Cell 41, 299657314.

658 Schumacher, MA, Henderson, M, Zhang, H (2019). Structures of maintenance of carboxysome 659 distribution Walker-box McdA and McdB adaptor homologs. Nucleic Acids Res 47, 5950-5962.

660 Schumacher, MA, Ye, Q, Barge, MT, Zampini, M, Barillà, D, Hayes, F (2012). Structural mechanism of 661 ATP-induced polymerization of the partition factor ParF: Implications for DNA segregation. $J$ Biol Chem 662 287, 26146-26154.

663 Sengupta, M, Nielsen, HJ, Youngren, B, Austin, S (2010). P1 plasmid segregation: Accurate 664 redistribution by dynamic plasmid pairing and separation. J Bacteriol 192, 1175-1183.

665 Shaner, NC, Lambert, GG, Chammas, A, Ni, Y, Cranfill, PJ, Baird, MA, Sell, BR, Allen, JR, Day, RN, 666 Israelsson, M, et al. (2013). A bright monomeric green fluorescent protein derived from Branchiostoma

667 Sun, Y, Casella, S, Fang, Y, Huang, F, Faulkner, M, Barrett, S, Liu, LN (2016). Light modulates the 668 biosynthesis and organization of cyanobacterial carbon fixation machinery through photosynthetic 669 electron flow. Plant Physiol 171, 530-541.

670 Thanbichler, M, Shapiro, L (2006). MipZ, a spatial regulator coordinating chromosome segregation with 671 cell division in Caulobacter. Cell 126, 147-162.

672 Toro, E, Hong, S, McAdams, HH, Shapiro, L (2008). Caulobacter requires a dedicated mechanism to 673 initiate chromosome segregation. Proc Natl Acad Sci USA 105, 15435-15440.

674 Treuner-Lange, A, Aguiluz, K, van der Does, C, Gómez-Santos, N, Harms, A, Schumacher, D, Lenz, P, 675 Hoppert, M, Kahnt, J, Muñoz-Dorado, J, Søgaard-Andersen, L (2013). PomZ, a ParA-like protein, 676 regulates Z-ring formation and cell division in Myxococcus xanthus. Mol Microbiol 87, 235-53. 
680 Vecchiarelli, AG, Han, Y-W, Tan, X, Mizuuchi, M, Ghirlando, R, Biertümpfel, C, Funnell, BE,

681 Mizuuchi, K (2010). ATP control of dynamic P1 ParA-DNA interactions: a key role for the nucleoid in

682 plasmid partition. Mol Microbiol 78, 78-91.

683 Vecchiarelli, AG, Havey, JC, Ing, LL, Wong, EOY, Waples, WG, Funnell, BE (2013). Dissection of the 684 ATPase active site of P1 ParA reveals multiple active forms essential for plasmid partition. $J$ Biol Chem $685288,17823-7831$.

686 Vecchiarelli, AG, Mizuuchi, K, Funnell, BE (2012). Surfing biological surfaces: Exploiting the nucleoid 687 for partition and transport in bacteria. Mol Microbiol 86, 513-523.

688 Vecchiarelli, AG, Neuman, KC, Mizuuchi, K (2014). A propagating ATPase gradient drives transport of surface-confined cellular cargo. Proc Natl Acad Sci USA 111, 4880-4885.

690 Volante, A, Alonso, JC (2015). Molecular anatomy of ParA-ParA and ParA-ParB interactions during 691 plasmid partitioning. J Biol Chem 290, 18782-18795.

692 Youngren, B, Austin, S (1997). Altered ParA partition proteins of plasmid P1 act via the partition site to block plasmid propagation. Mol Microbiol 25, 1023-1030.

694 Zhang, H, Schumacher, MA (2017). Structures of partition protein para with nonspecific DNA and ParB 695 effector reveal molecular insights into principles governing Walker-box DNA segregation. Genes Dev 31, $696 \quad 481-492$.

697 Zhou, H, Schulze, R, Cox, S, Saez, C, Hu, Z, Lutkenhaus, J (2005). Analysis of MinD mutations reveals 698 residues required for MinE stimulation of the MinD ATPase and residues required for MinC interaction. $J$ 699 Bacteriol 187, 629-638. 
A

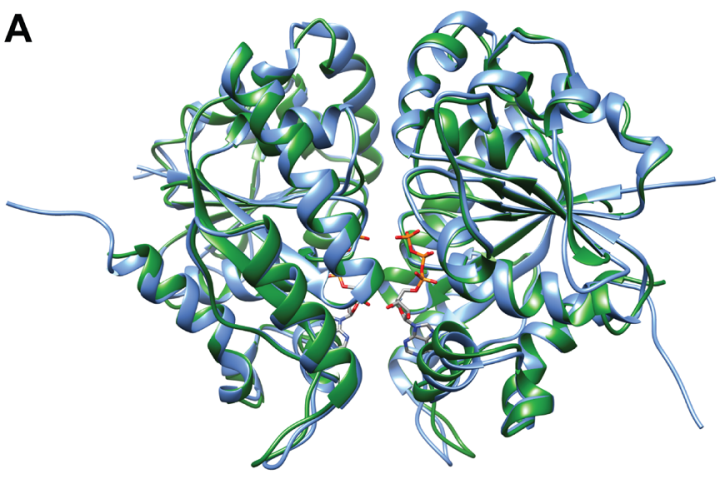

C

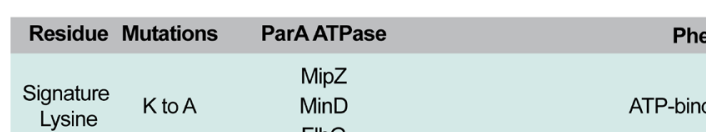

henotype

B Cargo

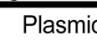

Plasmid

Chromosome

Chromosome

Divisome

Divisome

Divisome

Flagella

Chemotaxis cluster

Chemotaxis cluster

Carboxysome

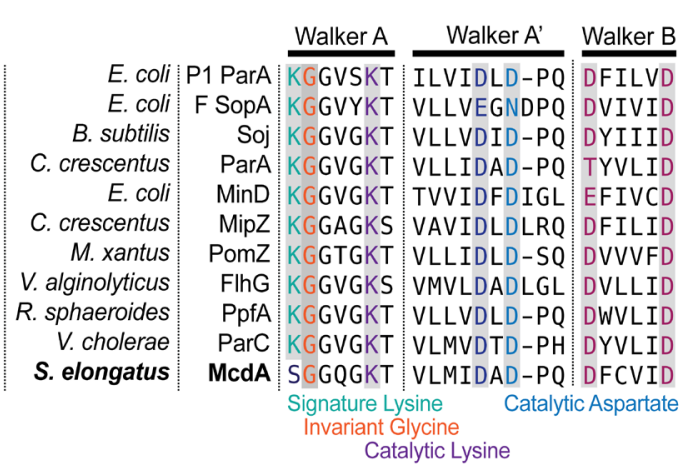

Catalytic Lysine

Figure 1: MedA shares structure and sequence conservation with ParA-type ATPases. (A) The crystal structure of Cyanothece McdA[D38A] (green; PDB entry 6nop) was superimposed on to the modelled structure of $S$. elongatus McdA (blue) with ATP molecules (sticks) in the sandwich dimer interface. (B) Amino acid sequence alignment of the Walker A, A' and B motifs conserved among ParA family ATPases. Invariant residues are shaded grey. The signature lysine (green), invariant glycine (orange) and catalytic lysine (purple) in the Walker A motif and the catalytic aspartate in the Walker A' motif were mutated in this study. (C) Summary of strategic mutations studied in ParA family members and their associated phenotypes; Cc: Caulobacter crescentus, Mx: Myxococcus xanthus. Refer to Table S1 for a more detailed summary of mutant phenotypes. 

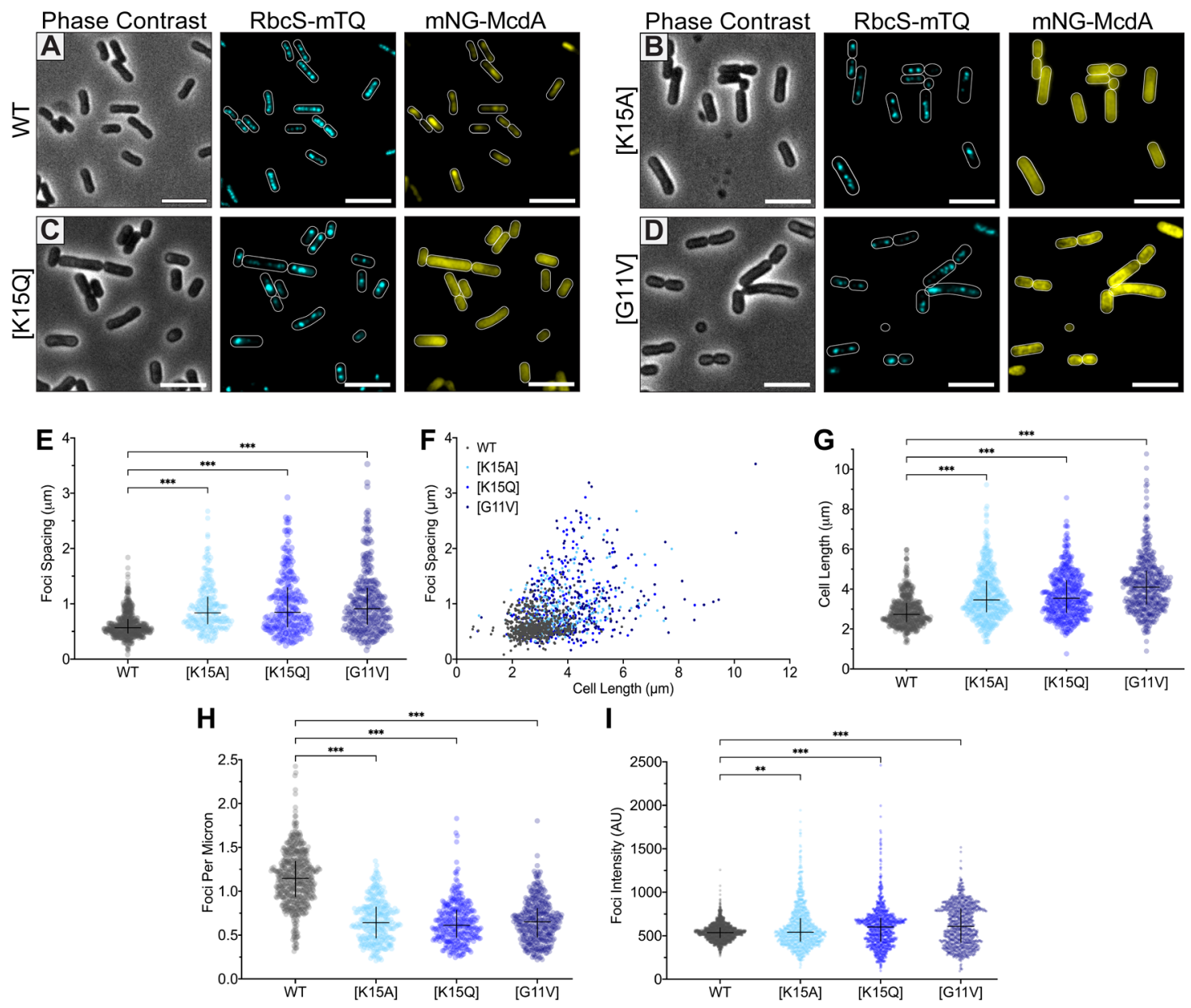

Figure 2: McdA mutants deficient in ATP binding and dimerization are unable to interact with the nucleoid and position carboxysomes. (A) mNG-McdA dynamically oscillates and positions carboxysomes labelled with RbcS-mTQ (cyan). (B-D) ATP-binding (K15A and K15Q) and dimerization
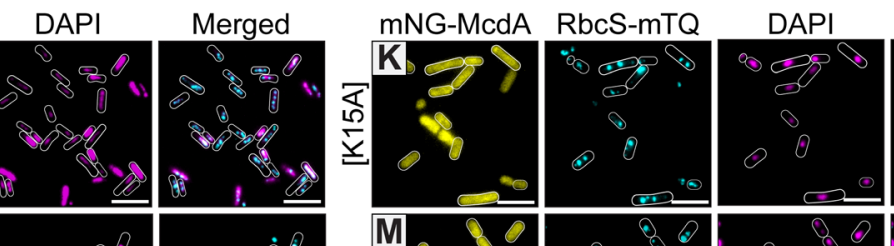

Merged
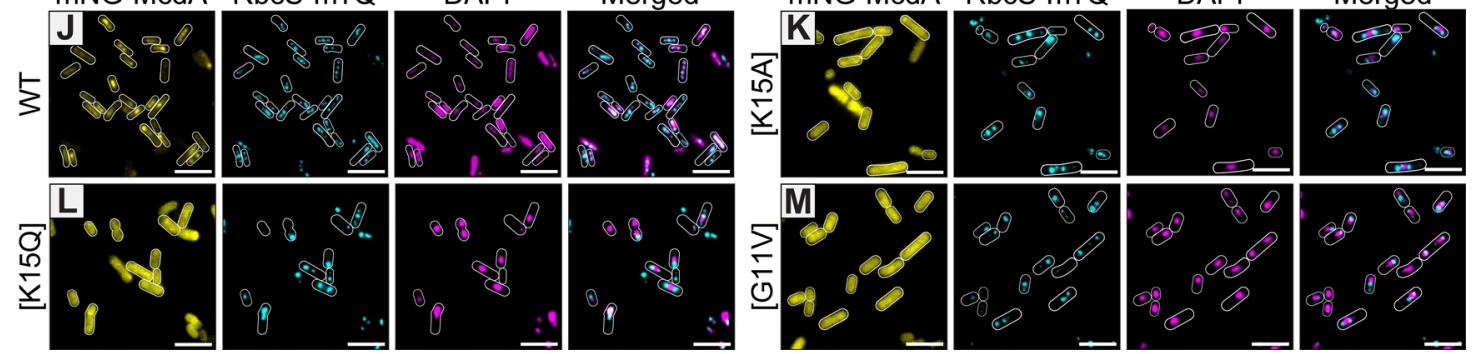

(G11V) mutants of mNG-McdA no longer oscillate and carboxysomes aggregate. Cell outlines in fluorescent channels are based on the Phase Contrast image. (E) Spacing between carboxysome foci in the same cell. (F) Distribution of spacing between carboxysome foci as a function of cell length. For $(\mathbf{E})$ and (F): WT $n=558$ cells; $n>200$ cells per mutant strain. (G) Cell lengths of specified strains. $n>400$ cells per strain. (H) Number of carboxysome foci per unit cell length for each strain. WT $n=578$ cells; $n$ $>300$ cells per mutant strain. (I) Carboxysome foci intensity for each cell strain (Arbitrary Units $=$ AU). WT $n=1925$ foci; $\mathrm{n}>1100$ foci per mutant strain. Data represent median with interquartile range. $* * * \mathrm{p}$ $<0.001, * * \mathrm{p}<0.005$ by Kruskal-Wallis test. (J-M) Microscopy images of cells with ciprofloxacincompacted nucleoids. mNG-McdA and the specified variants (yellow), carboxysome foci (cyan) and DAPI-stained nucleoids (magenta). Carboxysome and DAPI channels are merged. Scale bars: $5 \mu \mathrm{m}$. 

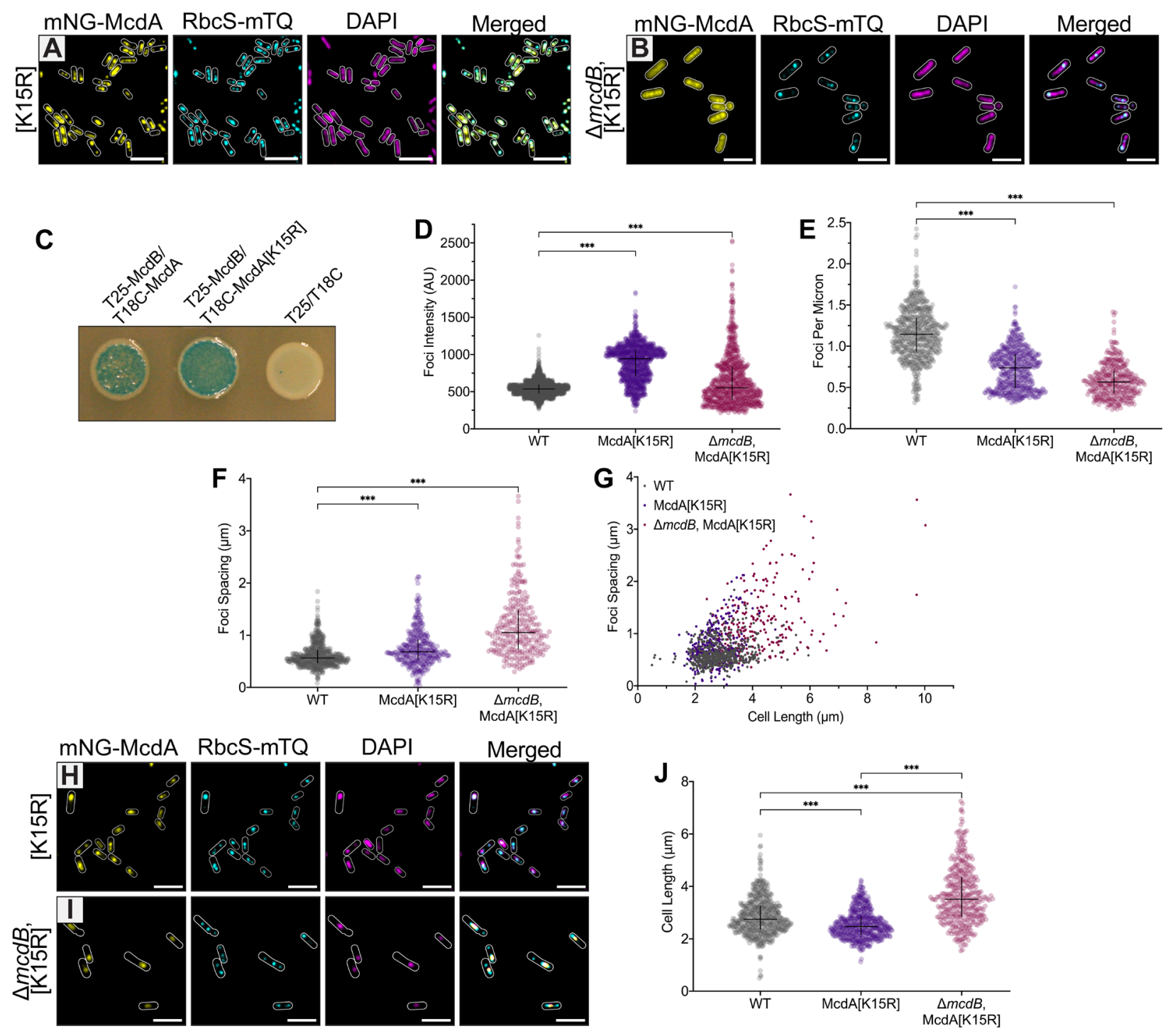

Figure 3: The ATP-Trap mutant MedA[K15R] irreversibly locks McdB-bound carboxysomes onto the nucleoid. (A) Microscopy images of mNG-McdA[K15R] (yellow), RbcS-mTQ-labelled carboxysomes (cyan) and DAPI-stained nucleoid (magenta). Merged image overlays mNG-McdA[K15R] and RbcS-mTQ-labelled carboxysomes. (B) Microscopy images of mNG-McdA[K15R] in $\Delta m c d B$ background strain. Merged image shows carboxysome and DAPI signals. (C) Bacterial two-hybrid interaction assay between the indicated protein pairs. Image is representative of three independent experiments. (D) Carboxysome foci intensity for specified cell strains. (Arbitrary Units $=$ AU). WT $n=$ 1925 foci; $n>800$ foci per mutant strain. (E) Carboxysome foci number as a function of cell length. WT $n=578$ cells; $n>370$ cells of mutant strains. (F) Spacing of carboxysome foci. WT $n=558$ cells; $n>$ 250 cells of mutant strains. (G) Distribution of spacing between carboxysome foci as a function of cell length. WT $n=558$ cells; $n>380$ cells of mutant strains. (H) Microscopy images of mNG-McdA[K15R] (yellow), carboxysome foci (cyan) and DAPI-stained nucleoid (magenta) with ciprofloxacin treatment. Merged image shows carboxysome and DAPI signals. (I) Microscopy images of mNG-McdA[K15R] (yellow) in $\triangle m c d B$ background strain, carboxysome foci (cyan) and DAPI-stained nucleoid (magenta) with ciprofloxacin treatment. Merged image overlays carboxysome, mNG-McdA[K15R] and DAPI. (J) Cell lengths of specified strains. WT $n=558$ cells; $n>250$ cells of mutant strains. Scale bars: $5 \mu \mathrm{m}$. 
A

\begin{tabular}{r|r} 
Alkalinema sp. CACIAM & SGGQGKT \\
Calothrix sp. 336/3 & SGGQGKT \\
Aphanothece hegewaldii CCALA 016 & SGGT \\
Cyanosarcina cf. burmensis CCALA 770 & SGGQGKT \\
Fremyella diplosiphon Fd33 & SGGQGKT \\
Nostoc calcicola FACHB-389 & SGGQGKT \\
Nostoc minutum NIES-26 & SGGQGKT \\
Nostoc sp. 213 & NGGQGKT \\
Nostoc sp. 5183 & SGGQGKT \\
Nostoc sp. ATCC 53789 & SGGQGKT \\
Nostoc sp. KVJ20 & SGGQGKT \\
Nostoc sp. PCC 7524 & SGGQGKT \\
Phormidium tenue NIES-30 & SGGQGKT \\
Spirulina subsalsa & SGGQGKT \\
Tolypothrix sp. NIES-4075 & SGGQGKT \\
Synechococcus sp UTEX 2973 & SGGQGKT \\
Synechococcus elongatus UTEX3055 & SGGQGKT \\
Synechococcus elongatus PCC 6301 & SGGQGKT \\
Synechococcus elongatus PCC 11801 & SGGQGKT \\
Cyanothece sp. PCC 7424 & SGGQGKT \\
Synechococcus elongatus PCC 7942 & SGGQGKT
\end{tabular}

Walker A C-terminal Half

SVKGYGSLVRTLDLLQTLQDVGATDAQVLGILPFRDRWIGNTQTQESR STKGVNSFIRTLELVQSLENLGAFTGSILGVVPFRDKWFGRSQSKDSA SVKGYGSLVRTLDLLSGLQDVGATNAQVLGVLPFRDRWFGNTQAQESR TVKGFGSLVRTLDLLTNLKEVKATNAELLGVLPFRDRWIGMNQSTESR SVKGYGSLVRTLDLLSGLRDVGATNAEILGVLPFRDRWFGNTQAQESR NVKGVNSLVETLAFLDEQADIEAFNGQVLGIVPFRDRWVGNTQTKESR SVKGYGSLVRTLDLLSGLRDVGATNAQVLGVLPFRDRWFGNTQAQESR SVKGYGSLVRTLDLLSGLRDVGATNASILGVLPFRDRWFGNTQAQESR SSKGVNSLIRTLSLVEELQEIDAFSG IVLGILPFRDKWVGNNQVAQSK SSKGVNSLIRTLSLVEELQEIDAFSGIVLGILPFRDKWVGNNQVAQSK SSKGVNSLIRTLALIEELREIDAFSGEILGILPFRDKWVGNNQVAQSK SVKGYGSLVRTLDLLSGLQDVGATNAQVLGVLPFRDRWFGNTQAQESR SSKGVNSLIRTLSLVEELQEIDAFSGIVLGILPFRDKWVGNNQVAQSK SVKGYGSLVRTFDLLNGLRDVGATDAEVLGVLPFRDRWFGNTQAQESR TVKGYGSLIRTAEAVRELTEDGASDAKVLGVIPFRDRWVGRSRTKESD SLKGYGSLVRTLDLLKSMQNVRATQAQVLGVIPFRDRWIGNNQSTESR SVKGYGSLIRTLDLLNGLRDVGATDAEVLGVLPFRDRWFGNTQAQESR SSKGLNSLLRTLDLVAEMSEVEAFQGQILGILPFRDRWLGRTQAKQSQ SSKGLNSLLRTLDLVVEMTEVEAFQGQILGILPFRDRWLGRTQAKQSQ SSKGLNSLLRTLDLVAEMSEVEAFQGQILGILPFRDRWLGRTQAKQSQ SSKGLNSLLRTLDLVAEMSEVEAFQGQILGVLPFRDRWLGRTQAKQSQ STKGVNSLIRTLEIVQSLEKLGAFTGSILGVIPFRDKWFGLSQSKDSA SSKGLNSLLRTLDLVAEMSEVEAFQGQILGILPFRDRWLGRTQAKQSQ McdA Signature Lysine
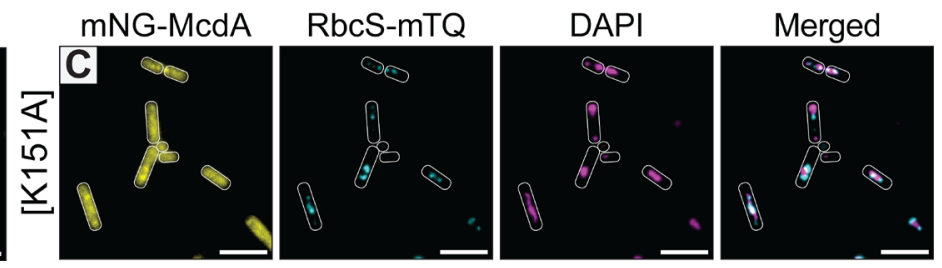

777
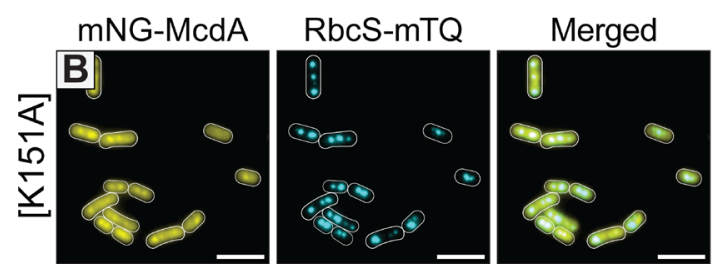

Figure 4: MedA is a member of an unstudied subclass of ParA-type ATPase characterized by a different signature lysine position. (A) Sequence alignment of McdA homologs possessing a serine residue in place of the signature lysine the Walker A box that co-occurs with an invariant lysine residue in the C-terminal half of proteins - the McdA signature lysine. (B) Microscopy images of mNGMcdA[K151A] and RbcS-mTQ-labelled carboxysomes (cyan). (C) Microscopy images of mNG$\operatorname{McdA}[\mathrm{K} 151 \mathrm{~A}]$ (yellow), carboxysome foci (cyan) and DAPI-stained nucleoid (magenta) with ciprofloxacin treatment. Merged image shows carboxysome and DAPI signals. Scale bars: $5 \mu \mathrm{m}$. 

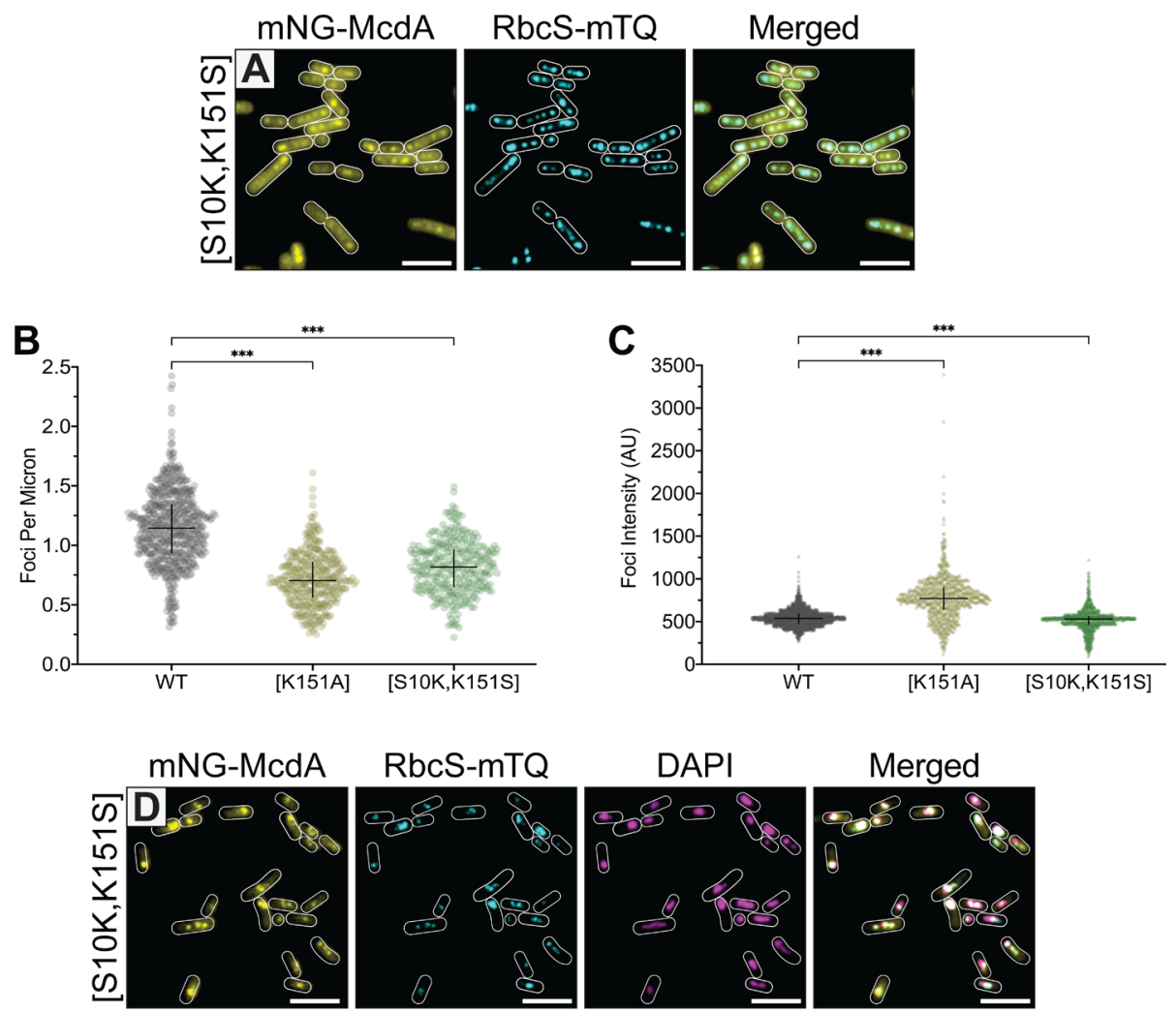

Figure 5: Carboxysomes are pseudo-positioned when the McdA signature lysine is moved into the classical Walker A box position. (A) Microscopy images of mNG-McdA[S10K, K151S] and RbcSmTQ-labelled carboxysomes (cyan). (B) Number of carboxysome foci per unit cell length. WT $n=578$ cells; $n>350$ cells of mutant strains. (C) Carboxysome foci intensity. (Arbitrary Units $=$ AU). WT $n=$ 1925 foci; $n>950$ foci from mutant strains. (D) Microscopy images of mNG-McdA[S10K, K151S] (yellow), carboxysome foci (cyan) and DAPI-stained nucleoid (magenta) with ciprofloxacin treatment. Merged image overlays carboxysome, mNG-McdA[S10K, K151S] and DAPI signals. (E) Cell lengths of specified strains. ns $=$ not significant by Kruskal-Wallis test. WT $n=561$ cells; $n>320$ cells of mutant strains. Scale bars: $5 \mu \mathrm{m}$. 
A

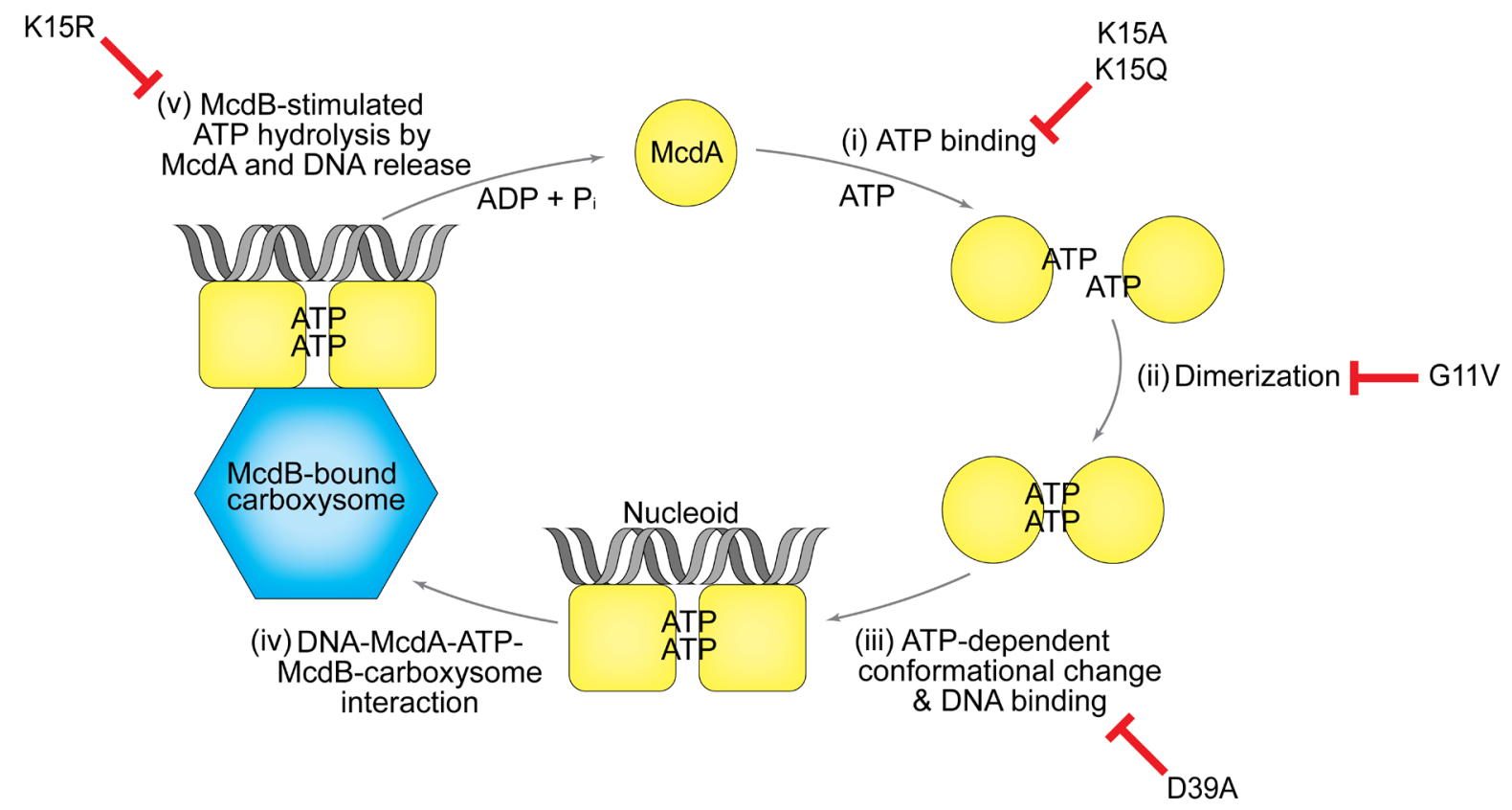

\section{B}

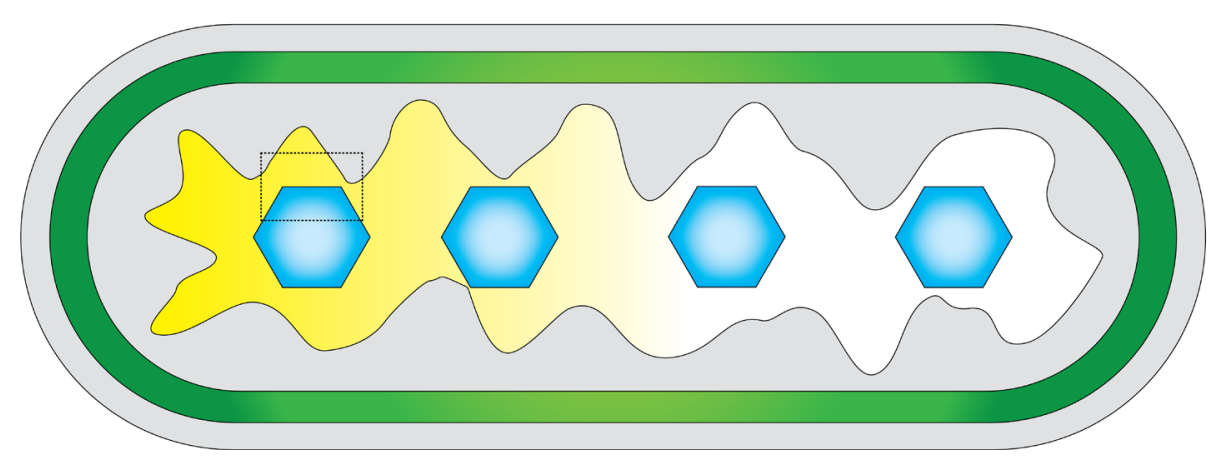

Figure 6: Model for ATP-cycling by MedA and associated functions in carboxysome positioning. (A) The ATPase cycle of McdA. Trap mutants of McdA identified in this study are indicated. (i) When unbound from ATP, McdA monomers are diffuse in the cytoplasm. (ii) Upon ATP-binding, McdA is competent for dimerization. (iii) ATP-bound McdA dimers must go through an ATP-dependent conformational change that licenses non-specific DNA binding to the nucleoid. (iv) McdB-bound carboxysomes are tethered via interactions with McdA-ATP dimers on the nucleoid. (v) McdB stimulates McdA ATPase activity and its release from the nucleoid in the vicinity of a carboxysome. (B) McdBbound carboxysomes are uniformly distributed as they continually move toward higher concentrations of McdA on the nucleoid. The dashed box indicates the cellular region magnified in (A). 


\section{Supplemental Information}

\section{Dissection of the ATPase active site of McdA reveals the sequential steps essential for carboxysome distribution}

Pusparanee Hakim $^{1}$ and Anthony G. Vecchiarelli ${ }^{1 *}$

*Corresponding Author Email Address: ave@umich.edu

This File Contains:

- $\quad$ Supplemental Figures S1 to S4

- $\quad$ Supplemental Movie Legend S1

- $\quad$ Supplemental Tables S1 and S2 

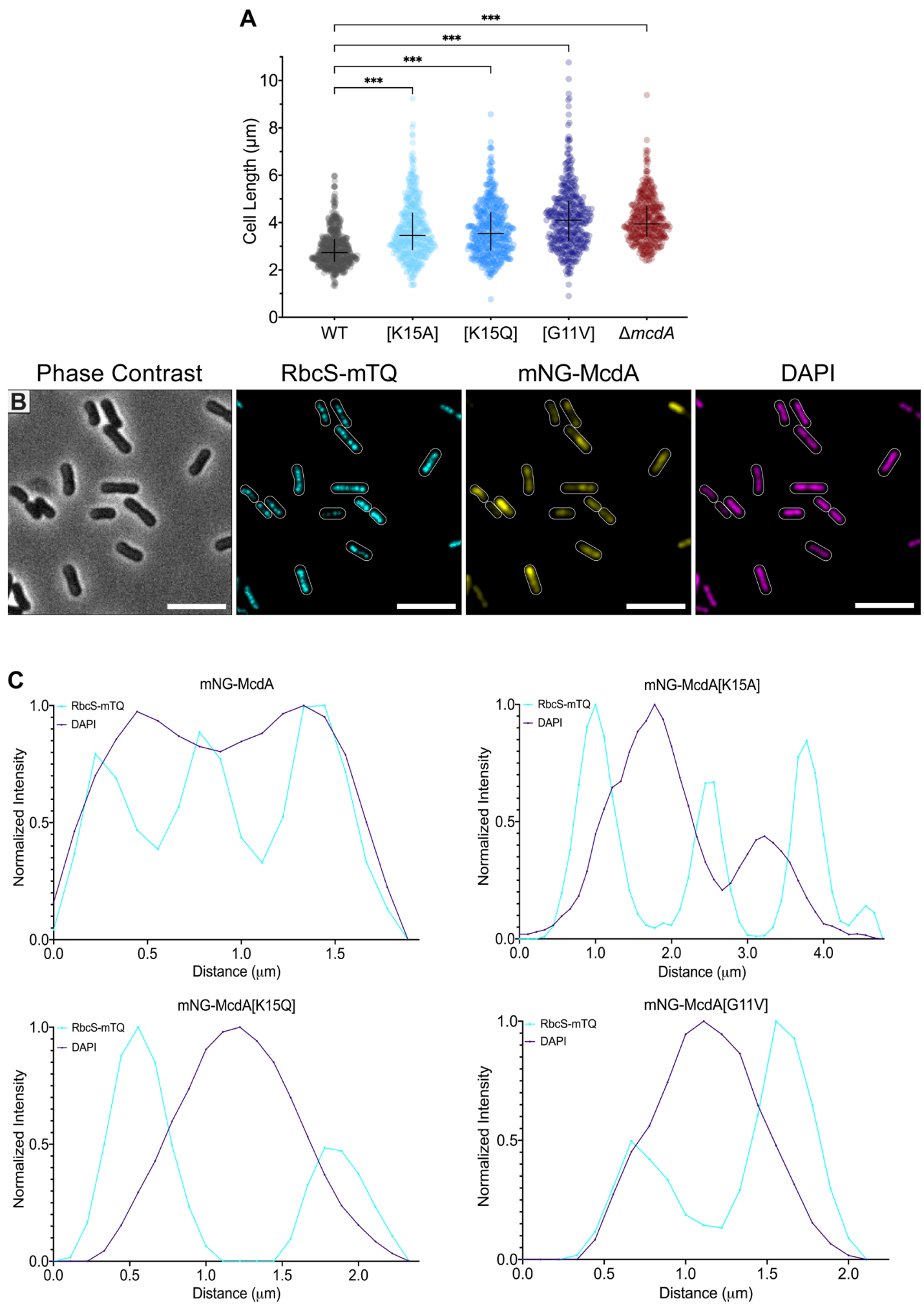

836 Figure S1: (A) Comparison of cell lengths among WT and specified mNG-McdA mutants and $\Delta m c d A$ strains. WT $n=558$ cells; $\mathrm{n}>380$ cells per mutant strains. (B) Microscopy images of mNG-McdA cells (Figure 2A) with DAPI-stained nucleoid (magenta). (C) Line scans of carboxysome and nucleoid signals of specified strains. Each line scan graph is a representative signal measurement of cells from each strain. 

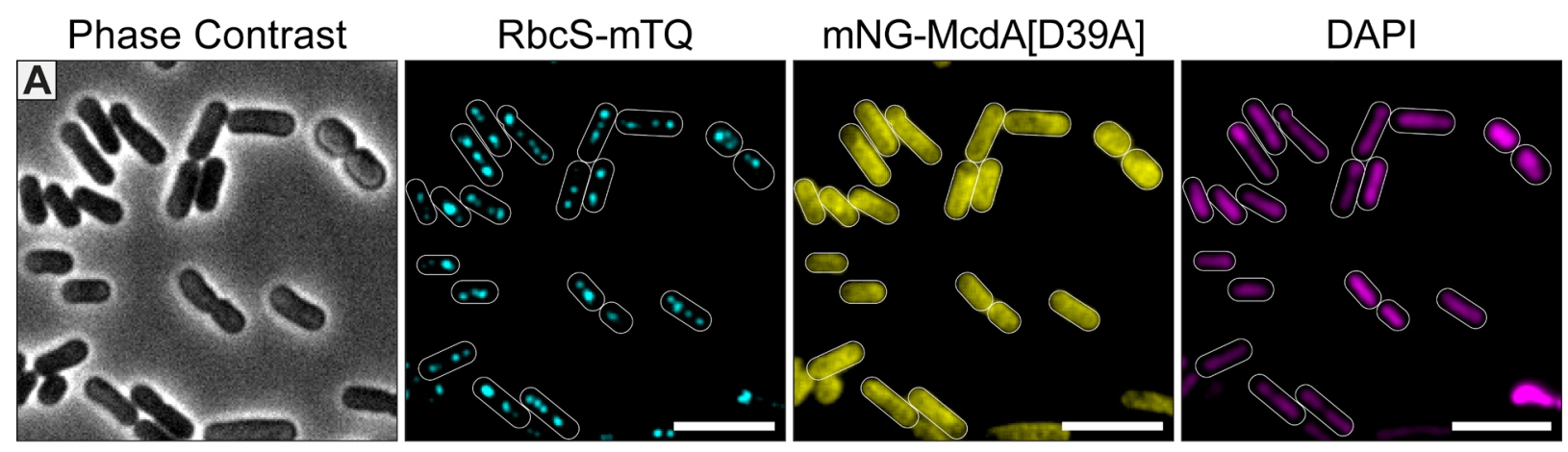

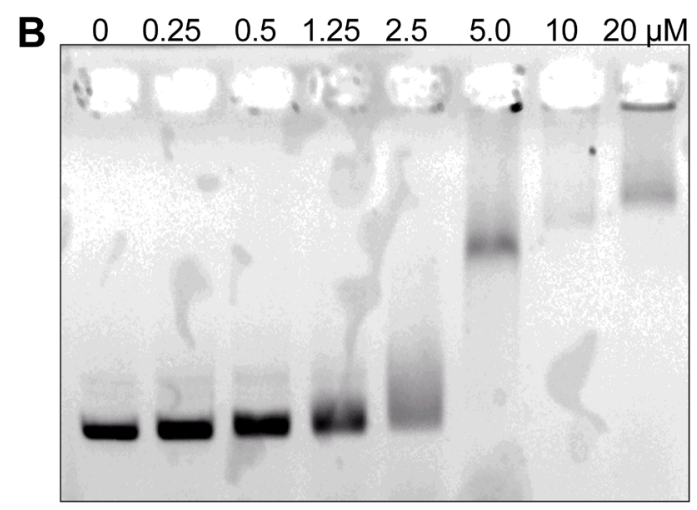

Cyanothece McdA + 1 mM ATP

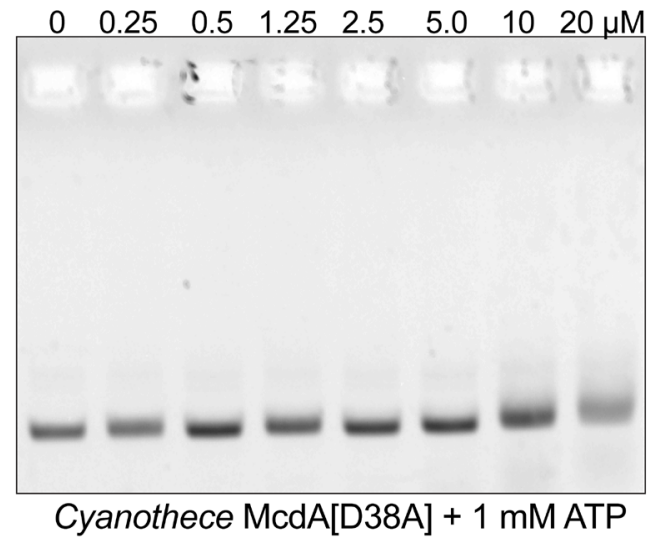

C

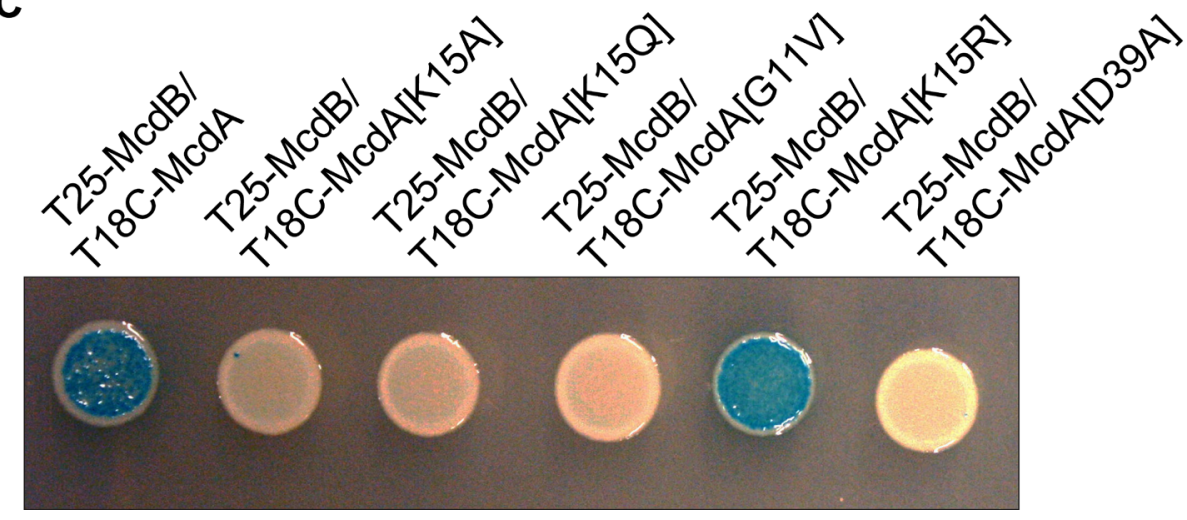

841 Figure S2: (A) Microscopy images of mNG-McdA[D39A] strain. (B) Bacterial two-hybrid interaction assay of McdB against the wild-type McdA or the specified mutants. Image is representative of three independent experiments. (C) Electrophoretic Mobility Shift Assay (EMSA) showing that wildtype $C t$ McdA binds and slows the migration of a non-specific plasmid DNA substrate in the presence of $1 \mathrm{mM}$ ATP while $C t \operatorname{McdA}[\mathrm{D} 38 \mathrm{~A}]$ does not. 


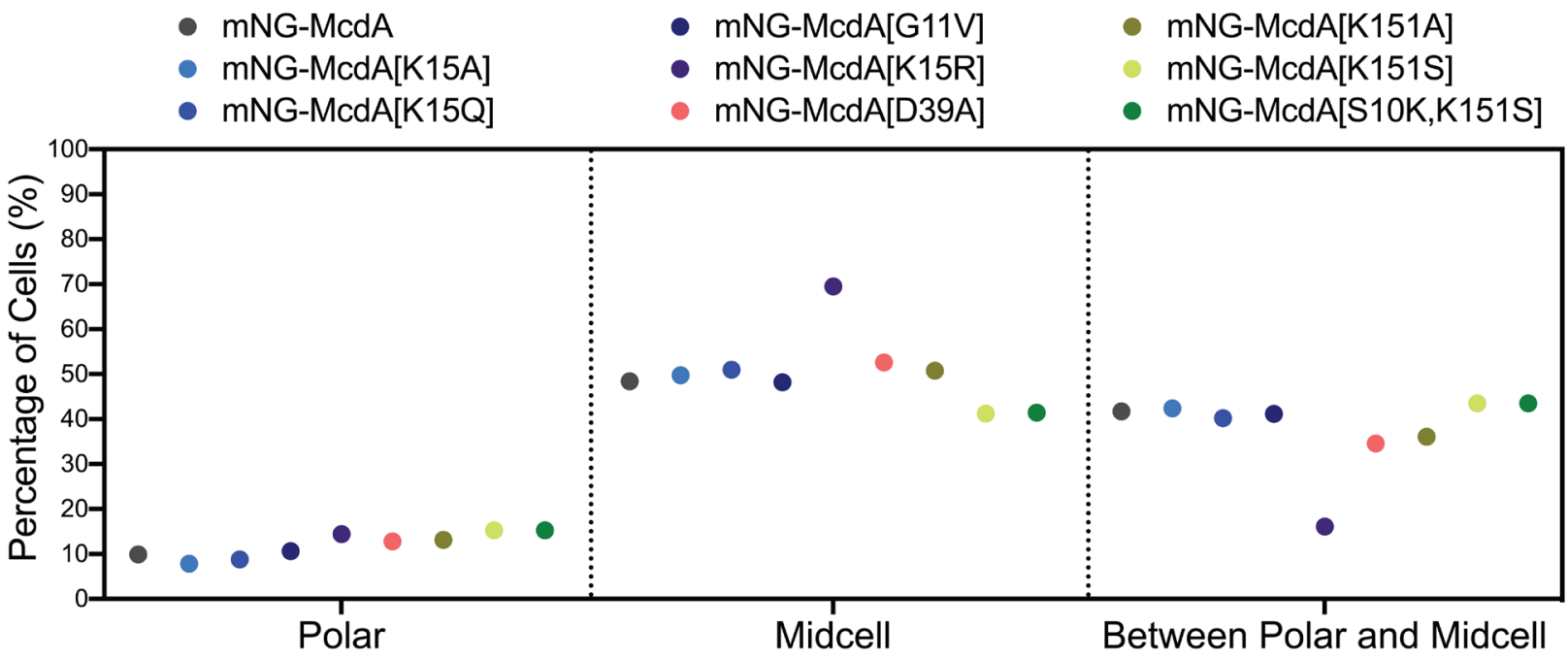

Figure S3: Binned subcellular localization of carboxysomes in the specified cell strains. Quantification was performed in MicrobeJ where carboxysome signals located within the region extending from the tip of the cell pole to a position on the medial axis located half the width away from the cell pole tip, are considered as "polar" localized. Carboxysome signals located within the region extending from the cell center to a position on the medial axis located half the width away from the cell center, are considered as "midcell" localized. Carboxysomes located between these two defined regions were grouped as "between polar and midcell". The McdA[K15R] cell population significantly deviants from all other McdA variants in regard to carboxysome foci positioning in the cell. WT $n=1000$ foci; $\mathrm{n}>800$ foci per mutant strain. 
A
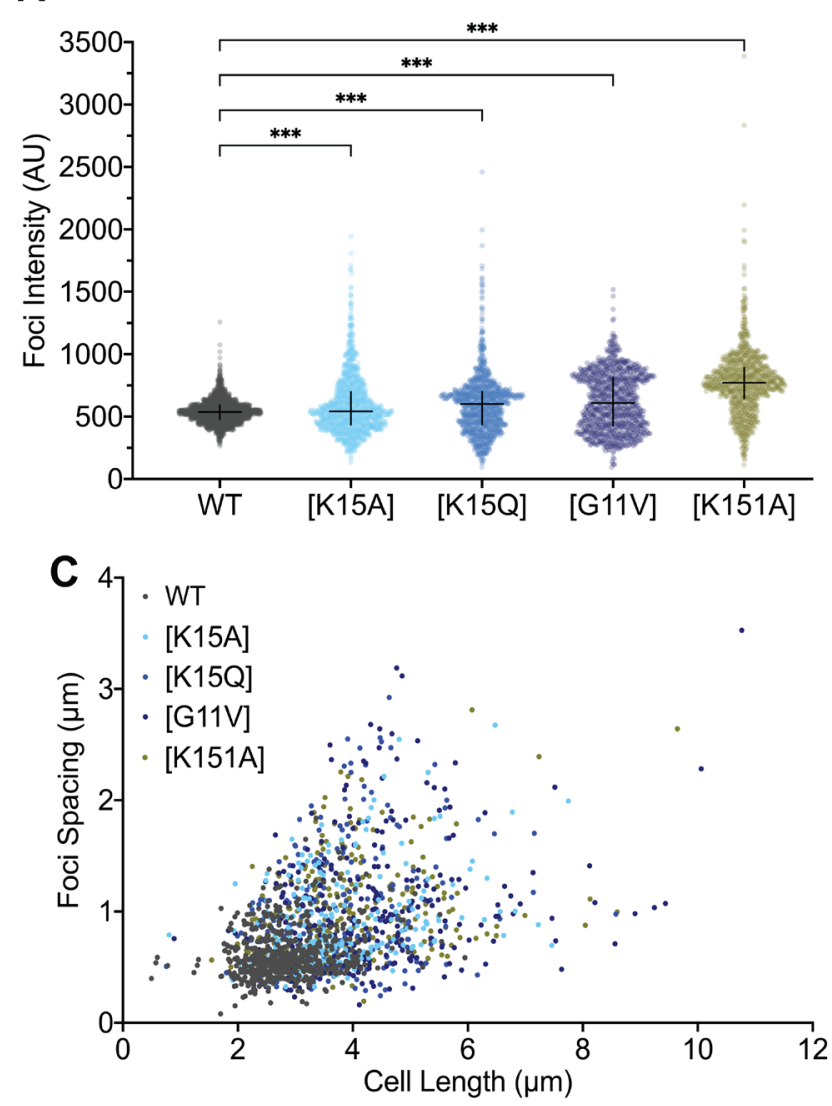

mNG-McdA[K151S]

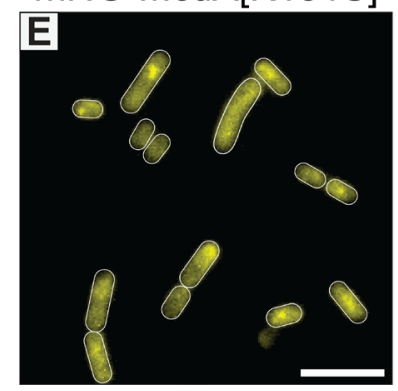

RbcS-mTQ

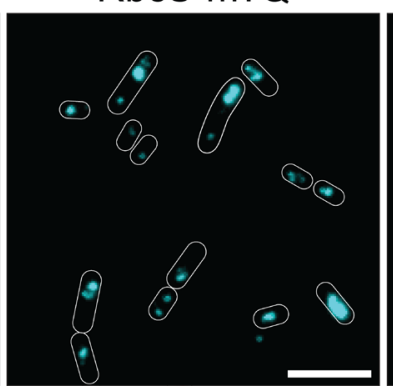

B

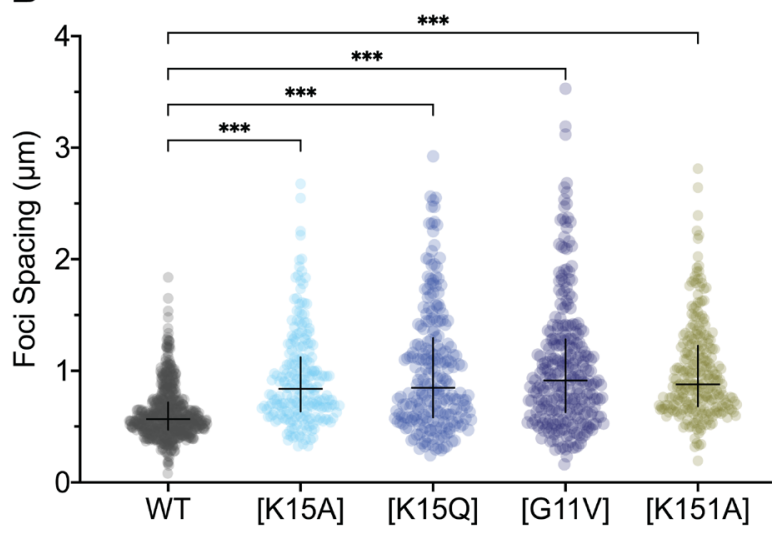

D

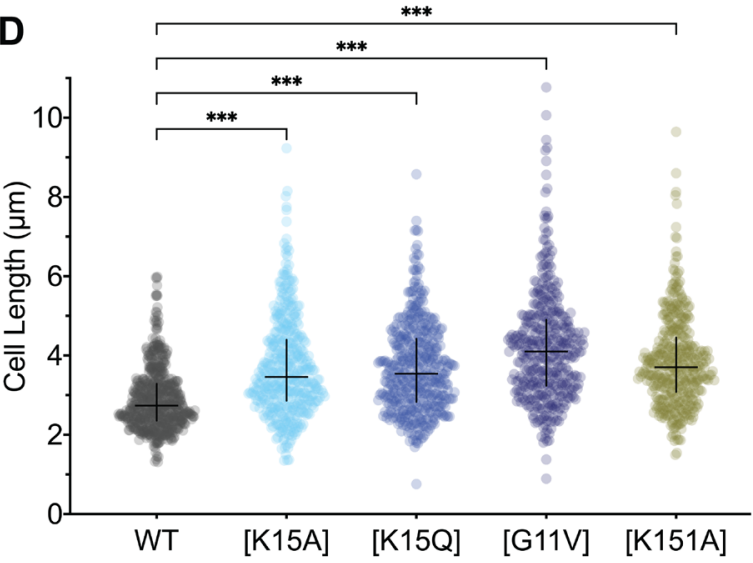

DAPI

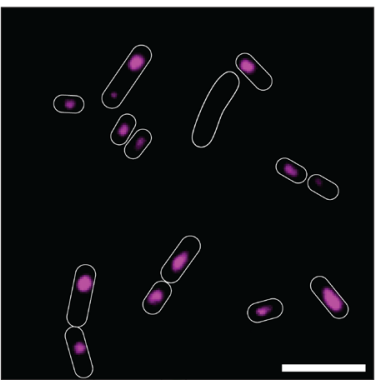

Merged

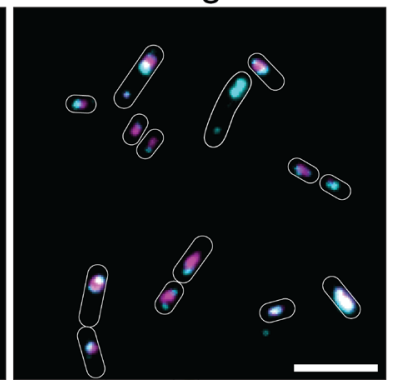

874

875

876

877

878

879

880

881

882

Figure S4: (A) Comparison of carboxysome foci intensity for specified strains. (Arbitrary Units $=$ AU). WT $n=1925$ foci; $n>1000$ foci per mutant strain. (B) Comparison of carboxysome foci spacing of specified cell strains. (C) Distribution of carboxysome spacing as a function of cell length in the specified strains. For (B) and (C): WT $n=558$ cells; $\mathrm{n}>220$ cells per mutant strain. (D) Comparison between the cell length of specified mNG-McdA mutants cell strains. WT $n=561$ cells; $n>365$ cells per mutant strain. (E) Microscopy images of mNG-McdA[K151S] (yellow), carboxysome foci (cyan) and DAPIstained nucleoid (magenta) when treated with ciprofloxacin. Merged image shows carboxysome and DAPI signals. 
bioRxiv preprint doi: https://doi.org/10.1101/2021.04.02.438200; this version posted April 2, 2021. The copyright holder for this preprint (which was not certified by peer review) is the author/funder, who has granted bioRxiv a license to display the preprint in perpetuity. It is made available under aCC-BY-NC 4.0 International license.

\section{SUPPLEMENTARY MOVIE LEGEND}

Movie S1: Live-cell fluorescence microscopy of wildtype S. elongatus cells (3 representative cells) treated with ciprofloxacin. mNG-McdA (yellow) continues to oscillate on ciprofloxacin-compacted nucleoids (DAPI) and carboxysomes (cyan) are still distributed across the compacted nucleoid. Movie was taken at 30 seconds per frame. Playback at $11 \mathrm{fps}$ (330x real-time).

\section{SUPPLEMENTARY TABLES}

\begin{tabular}{|c|c|c|c|c|}
\hline Residue & Mutations & ParA ATPase & Phenotype & References \\
\hline $\begin{array}{l}\text { Signature } \\
\text { Lysine }\end{array}$ & $\mathrm{K}$ to $\mathrm{A}$ & $\begin{array}{l}\text { MipZ } \\
\text { MinD } \\
\text { FlhG } \\
\text { MxParA }\end{array}$ & $\begin{array}{l}\text { ATP-binding deficient; Unable to interact with FtsZ; minicell formation } \\
\text { ATP and lipid-binding deficient, Unable to activate MinC } \\
\text { ATP-hydrolysis deficient; Decreased cellular motility } \\
\text { Dimerization deficient; Unable to bind DNA }\end{array}$ & $\begin{array}{l}\text { Corrales-Guerrero et al. } 2020 \\
\text { Zhou et al. } 2005 \\
\text { Ono et al. } 2015 \\
\text { Lin et al. } 2017\end{array}$ \\
\hline $\begin{array}{l}\text { Invariant } \\
\text { Glycine }\end{array}$ & $\mathrm{G}$ to $\mathrm{V}$ & $\begin{array}{l}\text { Soj } \\
\text { MipZ } \\
\text { PomZ } \\
\text { ParC } \\
\text { CcParA } \\
\text { MxParA } \\
\text { PpfA }\end{array}$ & $\begin{array}{l}\text { ATP-binding proficient; Dimerization-deficient } \\
\text { ATP-binding proficient; Dimerization-deficient; Minicell formation } \\
\text { ATP-binding proficient; Dimerization-deficient; Cells defective in division } \\
\text { ATP-binding proficient; Impaired interaction with ParP and CheA } \\
\text { ATP-binding proficient; dimerization deficient } \\
\text { Dimerization deficient; Unable to bind DNA } \\
\text { Impaired binding to TlpT and DNA }\end{array}$ & $\begin{array}{l}\text { Leonard et al. } 2005 \\
\text { Kiekebusch et al. } 2012 \\
\text { Schumacher et al. } 2017 \\
\text { Ringgaard et al. } 2011 \\
\text { Ptacin et al. 2010; } 2014 \\
\text { Lin et al. 2017 } \\
\text { Roberts et al. } 2012\end{array}$ \\
\hline & $\mathrm{K}$ to $\mathrm{A}$ & $\begin{array}{l}\text { Soj } \\
\text { PpfA }\end{array}$ & $\begin{array}{l}\text { ATP-binding deficient } \\
\text { Impaired binding to TIpT and DNA }\end{array}$ & $\begin{array}{l}\text { Leonard et al. } 2005 \\
\text { Roberts et al. } 2012\end{array}$ \\
\hline Catalytic & $\mathrm{K}$ to $\mathrm{Q}$ & $\begin{array}{l}\text { MipZ } \\
\text { PomZ } \\
\text { ParC } \\
\text { CcParA } \\
\text { SopA }\end{array}$ & $\begin{array}{l}\text { ATP-binding deficient; Minicell formation } \\
\text { ATP-binding deficient; Cells defective in division } \\
\text { ATP-binding deficient; Impaired interaction with ParP and CheA } \\
\text { ATP-binding deficient } \\
\text { Does not oscillate in vivo; No SopB-stimulated increase of ATPase activity }\end{array}$ & $\begin{array}{c}\text { Kiekebusch et al. } 2012 \\
\text { Schumacher et al. } 2017 \\
\text { Ringgaard et al. } 2014 \\
\text { Ptacin et al. 2010; } 2014 \\
\text { Hatano et al. 2007; Libante et al. } 2001\end{array}$ \\
\hline & $\mathrm{K}$ to $\mathrm{R}$ & $\begin{array}{l}\text { P1 ParA } \\
\text { MxParA } \\
\text { SopA } \\
\text { CcParA }\end{array}$ & $\begin{array}{l}\text { ATP-binding, dimerization and DNA-binding proficient; ATP-hydrolysis deficient } \\
\text { ATP-binding, dimerization and DNA-binding proficient; ATP-hydrolysis deficient } \\
\text { Does not oscillate in vivo; Reduced ATPase activity } \\
\text { Incomplete chromosome segregated; Minicells formation }\end{array}$ & $\begin{array}{c}\text { Fung et al. 2001; Hwang \& Vecchiarelli et al. 2013; } \\
\text { Vecchiarelli et al. } 2013 \\
\text { Lin et al. } 2017 \\
\text { Hatano et al. 2007; Libante et al. } 2001 \\
\text { Toro et al. } 2008\end{array}$ \\
\hline $\begin{array}{l}\text { Catalytic } \\
\text { Aspartate }\end{array}$ & $D$ to $A$ & $\begin{array}{l}\text { Soj } \\
\text { Mipz } \\
\text { MinD } \\
\text { PomZ } \\
\text { FlhG } \\
\text { CcParA } \\
\text { MxParA } \\
\text { PpfA }\end{array}$ & $\begin{array}{l}\text { ATP-binding, dimerization and DNA-binding proficient; ATP-hydrolysis deficient } \\
\text { ATP-binding, dimerization and DNA-binding proficient; ATP-hydrolysis deficient; } \\
\text { filamentous cells } \\
\text { ATP-binding, dimerization and DNA-binding proficient; ATP-hydrolysis deficient } \\
\text { ATP-binding, dimerization and DNA-binding proficient; ATP-hydrolysis deficient } \\
\text { ATP-binding proficient; ATP-hydrolysis deficient } \\
\text { ATP-binding, dimerization and DNA-binding proficient; ATP-hydrolysis deficient } \\
\text { ATP-binding, dimerization and DNA-binding proficient; ATP-hydrolysis deficient } \\
\text { Trapped in ATP-TIpT-DNA complex }\end{array}$ & $\begin{array}{c}\text { Leonard et al. } 2005 \\
\text { Thanbichler \& Shapiro 2006; Kiekebusch et al. 2012; } \\
\text { Corrales-Guerrero et al. } 2020 \\
\text { Park et al. } 2012 \\
\text { Treuner-Lange et al. 2013; Schumacher et al. } 2017 \\
\text { Ono et al. 2015; Schuhmacher et al. } 2015 \\
\text { Ptacin et al. 2010; } 2014 \\
\text { Lin et al. } 2017 \\
\text { Roberts et al. } 2012\end{array}$ \\
\hline
\end{tabular}

Table S1: Detailed summary of ATP-binding pocket mutations studied in ParA family members and their associated phenotypes; Cc: Caulobacter crescentus, Mx: Myxococcus xanthus. 


\begin{tabular}{|c|c|c|}
\hline Strain Name & Description/Genotype & Source \\
\hline JSM-206 & mNG-McdA + RbcS-mTQ & MacCready et al., 2018 \\
\hline AH-5 & mNG-McdA $[\mathrm{K} 15 \mathrm{~A}]+\mathrm{RbcS}-\mathrm{mTQ}$ & This study \\
\hline AH-6 & mNG-McdA[K15Q] + RbcS-mTQ & This study \\
\hline AH-7 & mNG-McdA[G11V] + RbcS-mTQ & This study \\
\hline AH-8 & mNG-McdA[D39A] + RbcS-mTQ & This study \\
\hline AH-9 & mNG-McdA[K15R] + RbcS-mTQ & This study \\
\hline AH-10 & mNG-McdA[K151A] + RbcS-mTQ & This study \\
\hline AH-11 & mNG-McdA[K151S] + RbcS-mTQ & This study \\
\hline AH-12 & mNG-McdA[S10K,K151S] + RbcS-mTQ & This study \\
\hline AH-13 & $\Delta m c d B+\mathrm{mNG}-\mathrm{McdA}[\mathrm{K} 15 \mathrm{R}]+\mathrm{RbcS}-\mathrm{mTQ}$ & This study \\
\hline RR-1 & $\Delta m c d A+\mathrm{RbcS}-\mathrm{mTQ}$ & Rillema et al., 2020 \\
\hline
\end{tabular}

Table S2. Cyanobacterial strains used in this study. 